Aşkun, V., Çizel, R. Çizel, B. (2021). “Ülkelerin İnovasyon Düzeyinin Sosyal Sermaye, Ekonomik Değer Algısı ve Politik Kültürle Karmaşık ilişkisi: Bulanık Küme Nitel Karşılaştırmalı Analiz", Eskişehir Osmangazi Üniversitesi iiBß Dergisi, 16(2), 317 - 340.

Doi: 10.17153/oguiibf.895910

Başvuru: 14.3.2021 Kabul: 6.4.2021

Araştırma Makalesi/Research Article

\title{
Ülkelerin İnovasyon Düzeyinin Sosyal Sermaye, Ekonomik Değer Algısı ve Politik Kültürle Karmaşık illişkisi: Bulanık Küme Nitel Karşılaştırmalı Analiz
}

\begin{tabular}{|c|c|}
\hline $\begin{array}{l}\text { Ülkelerin İnovasyon Düzeyinin Sosyal Sermaye, } \\
\text { Ekonomik Değer Algısı ve Politik Kültürle Karmaşık } \\
\text { iliş̧kisi: Bulanık Küme Nitel Karşılaştırmalı Analiz }\end{array}$ & $\begin{array}{l}\text { Complex Relationship of Countries' Innovation Level } \\
\text { with Social Capital, Economic Value Perception and } \\
\text { Political Culture: fsQCA }\end{array}$ \\
\hline Öz & Abstract \\
\hline $\begin{array}{l}\text { Çalışmada ülkelerin sosyal sermaye, ekonomik değer } \\
\text { algısı ve politik kültür ile inovasyon düzeyi bağlantısı } \\
\text { karmaşık uyarlanabilir sistem bakış açısıyla ve nitel } \\
\text { karşılaştırmalı analiz yöntemi ile incelenmiştir. } \\
\text { Çalışmada, Dünya Değerler Anketi, Avrupa Değerler } \\
\text { Anketi, Küresel İnovasyon Endeksinden alınan ikincil } \\
\text { veriler kullanılmıştır. Araştırma sonuçları, ülkelerde genel } \\
\text { güvenin, kurumlara güvenin, normların, ekonomik değer } \\
\text { algısının ve politik kültürün farklı konfigürasyonlarda } \\
\text { inovasyonu etkilediği ve bu koşullardan herhangi ikisinin } \\
\text { aynı anda az olmasının ise olumsuz etki yarattığı } \\
\text { göstermektedir. Inov̧ oluşuran } \\
\text { konfigürasyonlarda bireyci ülkeler ile kolektivist ülkeler } \\
\text { arasında farklılıklar ortaya çıkmaktadır. Çalışma, } \\
\text { karmaşık uyarlanabilir bir sistem olan inovasyon } \\
\text { hakkında yapılacak araştırmalara da yeni bir bakış açısı } \\
\text { kazandırabilir. }\end{array}$ & $\begin{array}{l}\text { In this study, in order to reveal such a causality } \\
\text { relationship, the connection between the countries' } \\
\text { social capital, economic value perception and political } \\
\text { culture and the innovation level was examined with a } \\
\text { complex adaptive system perspective and qualitative } \\
\text { comparative analysis method. Secondary data from the } \\
\text { World Values Survey, the European Values Survey, and } \\
\text { the Global Innovation Index were used in the study. The } \\
\text { results of the research show that general trust, trust in } \\
\text { institutions, norms, economic value perception and } \\
\text { political culture affect innovation in different } \\
\text { configurations and that less of either of these conditions } \\
\text { at the same time has a negative effect. There are notable } \\
\text { differences between collectivist countries and } \\
\text { individualist countries. The study can also provide a new } \\
\text { perspective for research on innovation, which is a } \\
\text { complex adaptive system. }\end{array}$ \\
\hline $\begin{array}{l}\text { Anahtar Kelimeler: Sosyal Sermaye, Ekonomik Değer } \\
\text { Algısı, Politik Kültür, İnovasyon Düzeyi, Bulanık Küme } \\
\text { Nitel Karşılaştırmalı Analiz }\end{array}$ & $\begin{array}{l}\text { Keywords: Social Capital, Economic Value Perception, } \\
\text { Political Culture, Innovation Level, Fuzzy-Set Qualitative } \\
\text { Comparative Analysis }\end{array}$ \\
\hline JEL Kodları: J00, LOO, M00 & JEL Codes: J00, LOO, M00 \\
\hline \multicolumn{2}{|l|}{$\begin{array}{c}\text { Araştırma ve } \\
\text { Yayın Etiği } \\
\text { Beyanı }\end{array}$} \\
\hline \multicolumn{2}{|c|}{ Yazar 1'in makaleye katkısı \%34, Yazar 2'nin makaleye katkısı \%33, Yazar 3'ün makaleye katkısı \%33'tür. } \\
\hline açısından ya da üçüncü taraflar aç & ından çalışmadan kaynaklı çıkar çatışması bulunmamaktadır. \\
\hline
\end{tabular}

\footnotetext{
1 Öğr. Gör., Akdeniz Üniversitesi, Demre Dr. Hasan Ünal Meslek Yüksekokulu, volkanaskun@gmail.com

2 Prof. Dr., Akdeniz Üniversitesi, İktisadi ve İdari Bilimler Fakültesi, Çalışma Ekonomisi ve Endüstri ilişsileri Bölümü, rabiacizel@akdeniz.edu.tr

${ }^{3}$ Prof. Dr., Akdeniz Üniversitesi, Turizm Fakültesi, Turizm İşletmeciliği Bölümü, beykan@akdeniz.edu.tr
} 


\section{Giriş}

İş insanları ve hükümetler tarafından yönetilen yeni ticaret ağları; dünyanın hemen her bölgesini, farklı fikirleri, malları, dinleri ve hatta hastalıkları daha hızlı şekilde tek bir küresel değişim sistemine bağlamaktadır. Son 500 yılda ticaret ve kapitalizmin de büyük etkisiyle, hızı üstel şekilde artan inovasyonun bu küresel değişime etkisi yadsınamaz. Dünya çapında yeni fikirlerin dolaşımı, 16. yüzyılda başlayan Bilim Devrimi sırasında modern bilim biçimlerinin ortaya çıkmasını teşvik ederken, 19. yüzyılda inovasyon ilk defa hükümetler, üniversiteler, araştırma kurumları ve yetkililerin yanı sıra iş insanlarının ana hedefi haline gelmiştir (Christian, 2016). Bu anlamda hükümetler, iş insanları ve üreticiler yenilikçi üretim ve nakliye yöntemlerinin değişmesiyle kârlarını artırabileceğini fark etmişler ve inovasyona daha fazla anlamlar yüklemişlerdir. İnsanlığın ilk tarıma başladığı büyük inovasyondan bu bahsedilen tarihsel süreçle birlikte bugüne bakıldığında teknolojik, finansal, politik ve örgütsel yenilikleri açıklamak adına birçok bileşenin birlikte değerlendirilmesi mümkün olmaktadır (Christian, 2018). Bu birçok bileşenin veya koşulun inovasyonu ne şekilde ortaya çıkardığını incelemek ise bu çalışmanın temel amacını oluşturmaktadır.

Bileşenlerle veya koşullarla ortaya çıkan inovasyonu anlamak adına karmaşık uyarlanabilir sistemlerden yararlanılabilir. İnovasyon, küresel ticaretin düzene sokulması, yeniliklerin teşvik edilmesi, bağışıklık sisteminin güçlendirilmesi, ekosisteminin sürdürülebilir olması, zihinsel hastalıkların tedavisi gibi 21. yüzyılın pek çok önemli konusu karmaşık uyarlanabilir sistemler (complex adaptive system-CAS) olarak ele alınmaktadır (Holland, 2014). CAS'ı ortaya çıkaran bileşenlerin kendi aralarındaki etkileşimlerini derinlemesine kavramak ise oldukça önemlidir. Bahsedilen bileşenler aslında başka bileşenlerle girdikleri etkileşimler karşısında öğrenen ve uyum sağlayan yapılara dönüşmektedir. Bileşenler veya koşullarla sürekli etkileşim içinde olan inovasyon ise CAS olarak incelemeye değer bir konudur.

Bu çalışmada; ekonomik değer algısı, sosyal sermaye ve politik kültür bileşenler veya koşullar olarak ele alınmaktadır. Ekonomik değer algısı kişilerin deneyimleri, beklentileri ve tutumları ile zaman ve mevcut koşullar içinde ekonomik durum değerlendirmesi olarak tanımlanmaktadır. Kişilerin ekonomik öznel algıları, ekonomik koşulların yenilikçi tutumlarla nasıl ilişkili olduğunu incelemek için önemli göstergelerdir (Gabel ve Whitten, 1997). Gruplar içinde veya arasında iş birliğini kolaylaştıran ortak normlar, değerler ve anlayışlarla birlikteki ağlar (OECD, 2001b: 41) şeklinde tanımlanan sosyal sermaye ise inovasyonu artan bir şekilde üretilebileceğini ortaya koymaktadır (Doh ve Ács, 2009). Politik kültür, politik bir sürece düzen ve anlam veren, politik sistemdeki davranışı yöneten temel varsayımları ve kuralları sağlayan tavırlar, inançlar ve duygular kümesi olarak tanımlanmaktadır (Pye, 1968). Farklı politik kültürlerin ulusal inovasyon girişimlerine yararlı bir basamak sağladığı savunulmaktadır (Pfotenhauer vd., 2016). Bu bilgilerin ışığında çalışmada, inovasyonu sosyal bir süreç olarak değerlendiren Rogers (2003)'ın yaklaşımıyla sosyal sermayenin, ekonomik değer algısının ve politik kültürün birbirleriyle etkileşen bileşenlerin veya koşulların ortaya çıkardığı inovasyon, karmaşık uyarlanabilir bir sistem olarak ele alınmaktadır. Bu CAS pragmatik bakış açısıyla koşullar ve inovasyon sonucu arasında bir nedensel ilişki aranması ve bunu da nitel karşılaştırmalı analizle gerçekleştirmek çalışmanın özgünlüğünü ortaya koymaktadır. Diğer yandan çalışmada kullanılan nitel karşılaştırmalı analizin kullanımının ülkemizde henüz yaygın olmaması ve bu bağlamda nedensel ilişki kurmayı hedefleyen bilimsel çalışmalara bir yol haritası olması ise bir başka özgünlük olarak değerlendirilmektedir. 
Çalışmada, sonuç değişkeni olarak ele alınan inovasyon Global Innovation Index (Küresel Inovasyon Endeksi - KIE) (2020) verilerinden alınmıştır. Bunu doğurabilecek koşullar olarak düşünülen sosyal sermaye (genel güven, kurumlara güven, normlar), ekonomik değer algısı ve politik kültür ilişkin veriler ise World Values Survey (Dünya Değerler Anketi - DDA) (2020) ve European Values Study (Avrupa Değerler Anketi - ADA) (2020) sonuçlarından alınmıştır. Bütün veriler nitel karşılaştırmalı analizin nomotetik yaklaşımıyla ülkelerin kültürel özellikleri de dikkate alınarak Şekil-1'deki modelle karşılaştırmalı olarak değerlendirilmiştir. Bu anlamda literatür bölümünde sosyal sermaye, ekonomik değer algısı ve politik kültür ile inovasyon arasındaki yazın incelenmesi yapılırken, karmaşıklık hakkında da detaylı bir paragraf bulunmaktadır. Veri ve yöntem bölümünde nitel karşılaştırmalı analizin ne olduğu ve nasıl ele alındığı konusunda detaylı bilgi verilmektedir. Ayrıca verilerden elde edilen 70 ülke özelinde yapılan analiz çıktıları bulgular bölümünde sunulmaktadır.

Şekil 1: İnovasyonun Karmaşık ilişkisinin Modellemesi

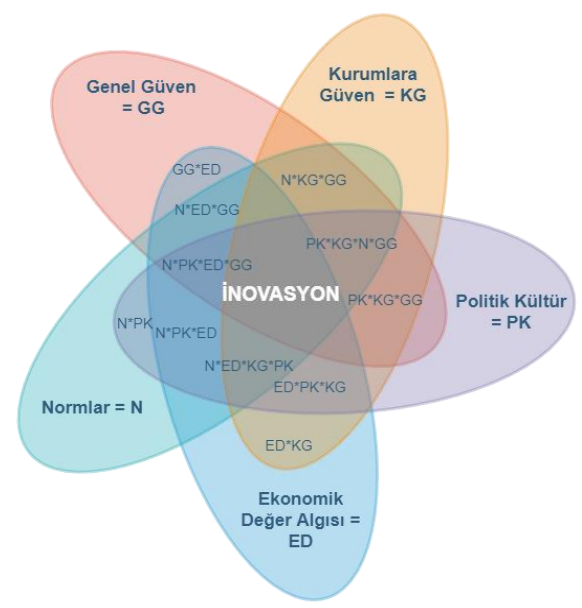

\section{Literatür Taraması}

Inovasyon, bir birey veya başka bir benimseme birimi tarafından yeni olarak algılanan bir fikir, uygulama veya nesnedir (Rogers, 2003: 14). Insan davranışı söz konusu olduğunda, bir fikrin nesnel olarak yeni olup olmadığı, ilk kullanımından veya keşfinden bu yana geçen zamanla ölçüldüğünde çok az önemlidir. Bir fikir bireye yeni geliyorsa, o bir inovasyondur. Bu bağlamda Rogers (2003: 17-18)'ın belirttiği üzere bir sosyal sistemin üyeleri tarafından algılanan bir inovasyonun beş özelliği vardır;

(1) Göreceli avantaj, bir inovasyonun yerini aldığı fikirden daha iyi olarak algılanma derecesidir.

(2) Uyumluluk, bir inovasyonun mevcut değerler, geçmiş deneyimler ve potansiyel benimseyenlerin ihtiyaçları ile tutarlı olarak algılanma derecesidir.

(3) Karmaşıklık, bir inovasyonun anlaşılması ve kullanılması zor olarak algılanma derecesidir.

(4) Denenebilirlik, bir yeniliğin sınırlı bir temelde denenebilme derecesidir.

(5) Gözlenebilirlik, bir inovasyonun sonuçlarının başkaları tarafından görülme derecesidir. 
Genel inovasyon yayılımı teorisini dile getiren Everett Rogers, inovasyonun teknik bir mesele değil, sosyal bir süreç olduğunu ifade etmektedir. Yeni fikirlerle ilgili mesajların, bir sosyal sistemdeki katılımcılar arasında iletişim kanalları aracılığıyla yayıldığı özel bir iletişim türüdür. Rogers bu süreçteki katılımcıları rollerine ve inovasyonu benimseme hızlarına göre adlandırmaktadır. Yenilikçiler, yeni fikirler icat eder; erken benimseyenler riske toleranslıdır yeni fikirleri erken benimseyebilirler; geç kabul edenler ise inovasyonun erken ve geç çoğunluğa yayılmasına tanık olduktan sonra muhafazakâr ve sınıf dışıdır. Bu bağlamda inovasyonun bileşen parçalarının ne olduğunu bulmalı, etkilerini tahmin etmeli ve istenen sonuçları üretmek için tüm bu değişkenlerin nasıl organize edileceği, harekete geçirileceği ve bir araya getireceği ortaya konulmalıdır. Çalışma kapsamında verilerinden yararlanılan KiE (2020) incelendiğinde, inovasyon bileşenleri yedi ana başlık altında ele almaktadır. Bunlardan bazılarına örnek olarak politik çevre, düzenleyici (mevzuat) çevre, iş çevresi, eğitim, yükseköğretim, AR-GE, bilgi ve iletişim teknolojileri, genel altyapı, ekolojik sürdürülebilirlik verilebilir (Ayrıntılı bilgi için bakınız KiE 2020). Bu alt başlıklardan ticaret, rekabet ve pazar ölçeği, inovasyon iş birliği, maddi olmayan varlıklar direk olarak algısal verilerden yararlanırken politik çevre, düzenleyici (mevzuat) çevre, iş çevresi, AR-GE, bilgi ve iletişim teknolojileri, genel altyapı, ekolojik sürdürülebilirlik, kredi ve yatırım ise üçüncü taraf veri sağlayıcılarından toplanmaktadır. Farklı yıllarda yayınlanan endeksten bileşenlerle çalışan araştırmalara bakıldığında, Wang, Wang ve Jiang (2020) iyi bir kurumsal ortam, yüksek düzeyde beşerî sermaye ve araştırmanın yapılmasının yüksek gelirli ve üst-orta gelirli ülkelerde yüksek inovasyon performansını teşvik edilebilecekken, mutlak suretle olgun piyasa koşullarına ihtiyaç duymadıklarını ortaya koymaktadırlar. Diğer yandan düşük-orta gelirli ülkelerin bu bileşenlerden hiçbirinin tek tek ele alındığında inovasyon performansını etkilemediği ve burada politika yapıcılara önemli işler düştüğünü belirtmektedirler.

Mas-Tur, Guijarro ve Carrilero (2020) sürdürülebilir kalkınma için girişimcilik özelliklerini belirlemeye çalıştıkları çalışmalarında, girişimcilerin algıladıkları fırsatları, algıladıkları yetenekleri, motivasyonları ve yüksek iş yaratma beklentilerine göre inovasyon arasında ülkeler özelinde farklılıklar olduğunu göstermektedir. Politik ve kurumsal boyutun inovasyon alanındaki hedefleri tutarlı bir şekilde karşılanmasından sorumlu olduğunu sonuç olarak ifade etmektedirler. Bir diğer araştırmada, Salehan, Kim ve Lee (2018) teknolojik zorunluluğun toplumları nasıl şekillendirdiği ve belirli grupların teknolojinin neden olduğu değerlere nasıl direndiğini tartıştıkları çalışmada yine bu bileşenlerden yararlanmaktadırlar. Dünyadaki ulusal kültürlerin de günden güne daha yüksek bireyci ve daha düşük güç mesafesine sahip hale gelmesinde inovasyon bileşenlerinin etkisi olduğundan bahsetmektedirler. Bu şekilde bir bileşen ağındaki karmaşık bir yapı olan inovasyonu ekonomik değer algısı, sosyal sermaye ve politik kültür gibi algısal bileşenlerle de ele almak oldukça önemli olduğu düşünülmektedir.

\subsection{Ekonomik Değer Algısı ve İnovasyon}

Bireysel olarak algılar, kişilerin çevrelerini, durumlarını anlamlandırmak adına duyumsal izlenimleri düzenleme ve yorumlama süreçlerine verilen isimdir (Robbins ve Judge, 2017: 209). Kişinin mevcut yaşanmışlıklarından kaynaklı olarak tutumları, amaçları, ilgi alanları, deneyimleri, beklentileri ile ilgili faktörlerle algı sürecinde içinde bulunan durum ve hedefin özellikleri kişinin algılarını belirlemektedir. Ekonomik değer algısı kavramı da kişilerin deneyimleri, beklentileri ve tutumları ile zaman ve mevcut koşullar içinde ekonomik durum değerlendirmesi olarak tanımlanabilmektedir. Kenny (2018)'in belirttiği üzere, nesnel ekonomik göstergeler, çeşitli bireysel faktörlere bağlı olarak ekonomik değer algılarında 
farklılıklar olacağını dikkate alamadıklarında sorunlu olabilmektedir. Bu nedenle kişilerin ekonomik öznel algıları, ekonomik koşulların yenilikçi tutumlarla nasıl ilişkili olduğunu incelemek için en iyi göstergelerdir (Gabel ve Whitten, 1997). Ekonomik değer algısı bugüne kadar uluslararası yazında ağırlıklı olarak ulusal ve uluslararası yapılan seçimler (Hansford ve Gomez, 2015; Lewis-Beck, Nadeau ve Elias, 2008; Park, 2019; Tilley, Garry ve Bold, 2008) gibi önemli konularda incelenmektedir.

Bunun yanı sıra ekonomik değer algısı ile farklı ülkelerde bankalara olan farklı güven düzeyleri (Fungáčová, Hasan ve Weill, 2019; Fungáčová ve Weill, 2018), sosyal sınıflar arasında hükümetlerden farklı düzeyde beklentiler (Turner ve Elordi, 1995), ülkeler arasındaki ekonomik farklııkları ne şekilde etkilediği (Marsh, 2009) ve demokrasilerde yüksek gelirli insanların görüşlerinin düşük gelirli insanların görüşlerine göre daha çok kamuoyunu etkilediği (Weakliem, Andersen ve Heath, 2005) gibi konularda çalışılmaktadır. Ekonomik değer algısı ve inovasyon arasındaki ilişkiyi inceleyen çalışmalara bakıldığında, Diwan, Tzannatos ve Akin (2018) Arap ülkeleri ile diğer ülkeleri karşılaştırdıkları çalışmalarında, yenilikçilere sosyal statü ödülleri veren bireyci kültürün inovasyon avantajı ile bireylerin grup çıkarlarını daha büyük ölçüde içselleştirdiği kolektivist kültürün koordinasyon avantajı arasında bir denge olduğunu belirtmektedirler. Bu bakış açısıyla bireyciliğin daha yüksek bir ekonomik büyüme oranına yol açan dinamik bir avantaja sahip olduğunu, kolektivizmin ise yalnızca statik verimlilik kazanımlarına yol açtığını ve bir düzeyde etkiye sahip olabileceğini göstermektedirler. Gorodnichenko ve Roland (2011), bireycilik-kolektivizm boyutunun uzun vadeli büyüme için önemli olan merkezi kültürel değişken olduğu ve ekonomik değer algısını ve ekonomik performansın diğer yönlerinden olan inovasyonu etkileyebileceğini göstermektedir. Beugelsdijk (2010), girişimcilik kültürü ve ekonomik büyüme arasındaki ilişkiyi incelerken ekonomik değer algısının girişimcilik kültüründe risk alıp almamasına etkisi olacağını ve bu bağlamda da inovasyonu buna göre etkileyeceğini belirtmektedir.

\subsection{Sosyal Sermaye ve İnovasyon}

OECD (2001b: 41), sosyal sermayeyi "gruplar içinde veya arasında iş birliğini kolaylaştıran ortak normlar, değerler ve anlayışlarla birlikteki ağlar" olarak tanımlamaktadır. Bu tanımdaki ağlar; arkadaş, aile, iş arkadaşlıkları vb. gruplar veya bireyler arasındaki ağlar olarak değerlendirilebilir. Ortak normlar, değerler ise sosyal ağlardan daha az somuttur. Sosyologlar bazen normlardan toplumun konuşulmamış ve büyük ölçüde sorgulanmamış kuralları olarak bahsederken toplumlar, değerlerinin değişip değişmediğini sıklıkla tartışırlar (Keeley, 2007: 103). Insanların hakkına, emniyetine ve güvenliğine saygı gibi değerler her sosyal grup için temeldir. Bu ağlar ile normlar ve değerler bir araya geldiğinde güven oluşur ve böylece insanların birlikte yaşaması, çalışması mümkün olabilmektedir. Bunun paralelinde kişiler ile gruplar arası güven ve kurumlara güven ile normlar sosyal sermayeyi oluşturan unsurlar olarak ele alınabilir. Diğer yandan sosyal sermaye ise iş birliği, değişim ve inovasyonu kolaylaştırarak bunları bir arada tutan (OECD, 2001a: 59) bir bileşen olarak ele alınabilir. Sosyal sermaye teorisyenleri, inovasyonun artan bir şekilde sosyal sermaye tarafından üretilebileceğini ve yüksek sosyal sermaye düzeyinin yalnızca toplumların etkin işleyişi için hayati önem taşımadığını, aynı zamanda yeni bilgi ekonomisindeki inovasyon üzerinde de olumlu bir etkiye sahip olduğunu öne sürmektedirler (Doh ve Ács, 2009).

Cáceres-Carrasco, Santos ve Guzmán (2020) sosyal sermaye, değerler, ekonomik gelişme ve inovasyon arasındaki ilişkiyi ortaya koydukları çalışmada sosyal sermaye altında ele aldıkları genel güvenin, kurumsal güvenin ve normların inovasyona etkisinin bekledikleri kadar 
olmadığını, ancak kişisel değerlerin sosyal sermayeden daha fazla etkisini belirtmektedirler. Bunun yanısıra muhafazakâr bir kültürün, düşük toleransı ve değişime karşı daha yüksek direnci nedeniyle, yetenek gelişimini durdurabileceği, bilgi yayılımını engelleyebileceğini ve gelir düzeyinden bağımsız olarak herhangi bir ülkede pazarlara girmenin önünde yeni engeller oluşturabileceği bu bağlamda inovasyona olumsuz etkisi olacağını göstermektedirler. Diğer yandan Doh ve Ács (2009) genel güvenden, kurumsal güvenden ve normlardan oluşan sosyal sermaye seviyesinin ülkenin inovasyon düzeyi üzerinde olumlu bir etkisi olduğunu belirtmektedir. Bu anlamda sosyal sermaye ve inovasyon arasındaki ilişkide ülkelerin kamu politikalarının da önemi olduğuna işaret etmektedirler. Knack ve Keefer (1997) sosyal sermayenin rolünü, bir toplumda güven ve sivil iş birliği normlarının nasıl güçlendirilebileceğini tanımlamaya çalışıldığında ortaya konduğunu, bu bağlamda bunların düşük olmasının inovasyondan yoksun olunacağını belirtmektedirler. Ayrıca girişimcilerin bu sosyal sermaye bileşenlerinden herhangi birinde azalma olduğunda suistimalleri takip ederken zaman kayıpları olacağını ve bu nedenle inovasyon yapma niyetlerinde azalma olacağının altını çizmektedirler. Brockman, Khurana ve Zhong (2018) genel güven ve inovasyon arasında güçlü bir ilişki olduğunu ve şayet ülkede güven eksikliği varsa inovasyonun da bundan ilk etkilenenlerden olacağını ifade etmektedirler. Genel güven, kurumsal güven ve normların inovasyonla ilişkisi olduğunu gösteren farklı zaman dilimlerinde çalışmaların (Cho, 2018; Dakhli ve De Clercq, 2004; Ghazinoory, Bitaab ve Lohrasbi, 2014; Putnam, 1993) olması konunun önemini ifade etmektedir.

\subsection{Politik Kültür ve İnovasyon}

Pye (1968)'a göre politik kültür, politik bir sürece düzen ve anlam veren ve politik sistemdeki davranışı yöneten temel varsayımları ve kuralları sağlayan tavırlar, inançlar ve duygular kümesidir. Aynı zamanda o politik kültürü, hem bir siyasi sistemin kolektif tarihinin hem de bu sistemin üyelerinin yaşam tarihlerinin bir ürünü olduğunu ve bu nedenle, kamusal olaylara ve özel deneyimlere eşit ölçüde kök saldığını belirtmektedir. Politik kültür geleneğindeki akademisyenler, politik güveni şekillendirmek için paylaşılan değerler etrafında değer yönelimlerinin ve topluluk uyumunun rolünü vurgular (Newton, 1997; Ostrom, 2015). Hardin (2002) ise temelde ilişkisel bir kavram olan güvenin, öznenin özellikleri ile güven nesnesi arasındaki etkileşimden ortaya çıkaracağını savunur. Bu nedenle politik kültür, vatandaşların devlet tarafından temsil edilen değerlerle anlaşmasından ve vatandaşların hükümet yapılarının, görevlilerinin ve süreçlerinin örnek oluşturan uygunluğu hakkında sahip oldukları inançlardan kaynaklanır.

Demokratik standartların ihlal edildiği ülkelerde, yüksek demokratik değerlere sahip bireylerin politik kültürleri düşük olacaktır (Kołczyńska, 2020: 5). Eğer devlet kurumlarına olan yüksek güven, kurumsallaşmış demokrasilerde, vatandaşların değerleri ve siyasi sistem tarafından temsil edilen değerler arasında yüksek bir uyumu işaret ediyorsa, güven en yüksek demokratik yönelim haline gelecektir. Bireyler ise inovasyon konusunda gerekli öncelikleri ve bunun gerçekleşmesi için gereken bileşenleri değerlendirecektir. Bu bağlamda politik kültür ile inovasyonla ilgili çalışmalara bakıldığında, van der Molen vd. (2019) Hollanda özelinde yaptıkları çalışmayla politika yapıcılar, uzmanlar ve toplumsal kuruluşların temsilcileri arasında kapsayıcı müzakerenin anahtar rol oynadığı, fikir birliğine ve iş birliğine dayalı politik kültüre sahip bir toplumun bilim ve inovasyon konusunda da başarılı olacağını ortaya koymaktadırlar. Pfotenhauer vd. (2016) kompleks uluslararası bilim, teknoloji ve inovasyon ortaklıklarının Birleşik Krallık, Abu Dabi, Portekiz ve Singapur'daki hükümetler arasında ne şekilde yapııdığını 
analiz ettikleri çalışmada politik kültürün bu ortaklıkların oluşumunda oldukça önemli olduğunu belirtmektedirler. Bu ortaklıklarda, farklı politik kültürlerin ulusal inovasyon girişimlerine yararlı bir basamak taşıdığını ve aynı zamanda program değerlendirmesine yönelik daha özel uyarlanmış yaklaşımlar sağladığını savunmaktadırlar. Son olarak bir bölgenin politik kültürüne bakış açısındaki farklılıkların, hükümetlerinin paydaş katılımına izin verme ve ekonomik olarak verilen fırsatları inovasyon yönünde aktif olarak keşfetme ve takip etme eğilimini belirledikleri için önemlidir (Arnstein, 1969; Hausmann ve Rodrik, 2003; Kroll, 2017).

\subsection{Karmaşıklık Teorisinden Karmaşık Uyarlanabilir Sistemlere}

Doğa bilimlerinde başlayan ve farklı öncül disiplinlerin (termodinamik, sibernetik ve kaos teorisi gibi) bir araya gelmesiyle ortaya çıkan karmaşıklık teorisi, bugün karmaşık sistemi tanımlamak, ölçmek ve anlamak için büyük ölçüde disiplinler arası bir proje oluşturmaktadır. Her şeyden önce karmaşıklığın ne olduğuna dair kabaca bir tanım sunmak gerekir. Karmaşıklık bizim tanımımızla, bugün bilinen evrenin ilk oluşum anı olan büyük patlamadan yaşadığımız kültüre kadar yaklaşık 13,8 milyar yıldan fazla süredir birbirinden farklı durumlar ve koşullar altında ortaya çıkan, sürdürülebilen ve artan bir sistemin parçasını oluşturan birçok farklı ve etkileşen bileşen tarafından karakterize edilen tüm fenomenlerdir. Karmaşıklık teorisi, doğa bilimleri ve matematikten beşerî bilimler ve sosyal bilimlere yayılmıştır ve karmaşıklık ile ilgili ilk çalışmalar Alfred North Whitehead, William James, Friedrich Nietzsche ve Henri Bergson tarafından yapılmıştır (Connoly, 2013: 29). Bunların yanı sıra Gilbert Simondon, Gilles Deleuze ve Félix Guattari gibi filozoflar da karmaşıklık fikirleri üzerine çalışmışlardır (Williams, 2020: 4).

Karmaşık sistemlerin bütünsel olarak incelenmesi gerekir, parçalar arasındaki ilişkiler, parçaların kendileri kadar önemlidir ve ilişkiler asimetrik olma eğilimindedir. Disiplinler arası doğası göz önüne alındığında, tek bir karmaşıklık teorisi yoktur ve ayrıca bu bilgi alanını sosyal bilimler ve beşerî bilimler içinde yorumlamanın tek bir yolu da yoktur. Bununla birlikte CAS düşüncesi, herhangi bir sistemdeki bileşenlerin o sistemin tüm bileşenleri olduğunu ve birbirleriyle öngörülemeyen ve planlanmamış şekillerde etkileşime girip birbirleriyle bağlantı kurduklarını ileri sürer (Holland, 2012). Örneğin, hava ve su molekülleri bir hava sisteminde etkileşirken, bitkiler ve hayvanlar bir ekosistemde etkileşime girer. Kültürel karmaşıklık ise çeşitli yapı taşlarının ve bileşenlerin özelliklerini oluşturmak için bir araya getirildiği uyarlanabilir sistemlerdir. Bu bağlamda, kültürel karmaşıklık şu anda gözlemlenebilir evrende bildiğimiz en karmaşık sistemlerin bir koleksiyonudur.

İnovasyon gibi kültürel bağlamın yer aldığı karmaşık uyarlanabilir bir sisteminde en karmaşık sistemler arasında yer aldığı ifade edilebilir. Bu temel kavrayıştan çok şey çıkarılabilir. Buradan yola çıkarak, geleneksel araçları kullanan sosyal bilimciler genellikle sistemleri tuhaf şekillerde modellemekle sınırlandırdıkları (Miller ve Page, 2007) söylenebilir. Mevcut modeller, zaman ve mekânın çok az önemli olduğu bir dünyayla yüzleşmek zorunda olan oldukça statik, homojen durumlara odaklanır. CAS araştırmalarının en güçlü araçlardan biri, çok daha geniş bir model yelpazesinin keşfedilmesine olanak tanıyan bir dizi hesaplama tekniğidir. Bu araçlarla, herhangi bir sayıda heterojen temsilci, zaman ve mekân sınırlarına tabi olarak dinamik bir ortamda etkileşime girebilir. Bu anlamda inovasyon gibi CAS'ı açıklamak için asimetriği analiz eden nitel karşılaştırma analiz kullanılması önemlidir. Bu bağlamda bu çalışmada, geniş bir örneklem olarak ülkelerin verilerini sunan Global Innovation Index (Küresel İnovasyon Endeksi - KiE, 2020), World Values Survey (Dünya Değerler Anketi - DDA, 2020) ve European Values Study (Avrupa Değerler Anketi - ADA, 2020) sonuçlarından 
yararlanılmıştır. Belirlenen koşullara ilişkin verilerin farklı kaynaklarda toplanmış olması farklı anket verilerini kullanmayı zorunlu kılmaktadır.

\section{Veri ve Yöntem}

Çalışmada, Dünya Değerler Anketi (DDA) kapsamındaki teorik çerçevede tanımlanan sosyokültürel faktörlere ilişkin belirli veriler kullanılmıştır. DDA, sosyal ve politik yaşamı etkileyen sosyal ve kültürel değerlere ilişkin dünya çapında bir araştırmadır ve daha önce sosyo-kültürel faktörlerle inovasyonu birbirine bağlayan başka araştırmalarda kullanılmıştır (Cáceres-Carrasco vd., 2020; Doh ve Ács, 2009; Knack ve Keefer, 1997). Anket, dünya çapında farklı kültür, sosyo-ekonomik ve politik durumlara sahip ülkelerde yaşayan insanlara ilişkin inanç ve değerlerle ilgili verileri kişisel görüşmeler yoluyla toplamaktadır. Çalışmada, DDA (2020) ve Avrupa Değerler Anketi (ADA) (2020) verilerinden yararlanarak Tablo 1'de yer alan 70 ülkeden 116.606 kişiden toplanan ikincil veriler değerlendirmeye alınmıştır. Sosyal sermaye ile belirtilen kuramsal bileşen burada yazına uygun şekilde genel güven, kurumlara güven ve normlar şeklinde ele alınmıştır. Bu üç koşulla ek olarak ekonomik değer algısı ve politik kültür de koşul olarak değerlendirilmiştir. Her iki anket çalışması büyük ölçüde tamamlayıcı ülke kapsamı ile her dalgada birkaç ülkede bireysel düzeydeki verileri toplar. ADA Avrupa'ya odaklanırken dünyanın geri kalanına DDA anketleri yapılmaktadır. Anket içeriği ile ilgili her iki proje arasındaki koordinasyon ve iki veri setini uygun bir şekilde birleştirmek için araçların varlığı, araştırmacılara neredeyse küresel kapsama sahip zengin bir veri kaynağı sağlar. Bu iki projeden elde edilen beş farklı değişken çalışmada koşul olarak, inovasyon da sonuç olarak ele alınırken bu 70 ülkeye göre Küresel İnovasyon Endeksi (KiE) (2020)'nde yer alan inovasyon girdisi alt endeksindeki verilerinde yararlanılmıştır.

\subsection{Bulanık Küme Nitel Karşılaştırmalı Analiz}

Geleneksel nicel sosyal bilim, neredeyse tamamen korelasyonel analize dayanır. Çoklu regresyondan faktör analizine ve yapısal eşitlik modellerine kadar bu prosedürler için gerekli olan tek şey, matrise dahil edilen değişkenlerin ortalamaları ve standart sapmalarıyla birlikte iki değişkenli korelasyonlar matrisidir. Korelasyon katsayısının hesaplanmasında tamamen simetrik olduğunu anlamak önemlidir. Dolayısıyla, bir nedenin varlığı ile bir etkinin varlığı arasındaki bağlantıyı değerlendirmek için korelasyon kullanıldığında, nedenin yokluğu ile etkinin yokluğu arasındaki bağlantıyı eşit olarak test eder. Simetrik olduğu için korelasyon, kuramsal ilişkilere göre kördür. En yaygın küme-teorik ilişki, alt küme ilişkisidir. Örneğin, gelişmiş ülkelerin demokratik olduğu gözlemi ilişkiseldir; gelişmiş ülkeler demokratik ülkelerin bir alt kümesini oluşturur.

Korelasyonel ilişkilerin aksine, küme-teorik ilişkiler asimetriktir (Ragin, 2014: i26). "Gelişmiş ülkeler demokratiktir" iddiası, gelişmemiş ülkelerin demokratik olmamasını gerektirmiyor. Demokratik olan pek çok gelişmemiş ülke olabilir ve bunların varlığı, asimetrik olan ilk iddiaya karşı sayılmaz. Daha genel olarak hem aranan sonuçların yeterliliğini hem de paylaşılan koşulların gerekliliğinin değerlendirilmesi, temelde teorik ve asimetriktir. Neredeyse tüm günlük olaylar nedensel karmaşıklık gösterir. Bazı bireylerdeki belirli davranış kalıpları erdem olarak görülürken bazılarında ahlaksızlık olarak görülebilir. Bu gibi durumlarda bağlam önemli bir rol oynar. Bunun nedeni, insanın nedenselliğe ve genel olarak olaylara temelde bütünsel bakmasıdır. Parçalar tek başına değil, oluşturdukları bütün bağlamında incelenir. Bir veya daha fazla unsuru değiştirmek çoğu kez bütünün nasıl algılandığını veya anlaşıldığını değiştirir ve bu da her bir parçanın anlamını etkiler. Bu da aslında araştırmacının ontolojik 
olarak sosyal gerçeklik arayışına cevap niteliğindedir (Byrne, 2013). Toplu duyguların, kitlesel davranışların ve genel olarak toplu eğilimlerin tahmini riskli bir iştir.

Tablo 1: Analizdeki Ülkeler ve Görüşme Sayısı

\begin{tabular}{|c|c|c|c|c|c|c|c|c|c|c|c|}
\hline Ülkeler & GG & KG & $\mathbf{N}$ & ED & PK & Ülkeler & GG & KG & $\mathbf{N}$ & ED & PK \\
\hline$A B D$ & 2.554 & 2.556 & 2.569 & 2.561 & 2.566 & İtalya & 2.276 & 2.274 & 2.269 & 2.270 & 2.253 \\
\hline Almanya & 687 & 3.685 & 3.689 & 3.671 & 3.661 & İzlanda & 1.621 & 1.623 & 1.614 & 1.620 & 1.563 \\
\hline Arjantin & .002 & 1.002 & 1.000 & 995 & 997 & Japonya & 1.329 & 1.333 & 1.333 & 1.323 & 1.268 \\
\hline Arnavutluk & 1.432 & 1.433 & 1.435 & 1.435 & 1.377 & Karadağ & 1.002 & 987 & 999 & 997 & 981 \\
\hline Avustralya & 1.805 & 1.805 & 1.798 & 1.802 & 1.775 & Kazakistan & 1.272 & 1.267 & 1.256 & 1.271 & 1.236 \\
\hline Avusturya & 1.643 & 1.641 & 1.637 & 1.640 & 1.629 & Kıbrıs & 991 & 988 & 998 & 999 & 991 \\
\hline Azerbaycan & 1.796 & 1.796 & 1.792 & 1.772 & 1.779 & Kırgızistan & 1.200 & 1.197 & 1.178 & 1.200 & 1.155 \\
\hline Bangladeş & 1.199 & 1.199 & 1.200 & 1.200 & 1.200 & Kolombiya & 1.520 & 1.520 & 1.520 & 1.520 & 1.520 \\
\hline Belarus & 1.540 & 1.533 & 1.541 & 1.543 & 1.521 & Makedonya & 1.115 & 1.109 & 1.112 & 1.095 & 1.105 \\
\hline $\begin{array}{l}\text { Birleşik } \\
\text { Krallık }\end{array}$ & 1.788 & 1.788 & 1.786 & 1.784 & 1.770 & Litvanya & 1.438 & 1.436 & 1.439 & 1.441 & 1.412 \\
\hline Bolivya & 2.067 & 2.067 & 2.065 & 2.062 & 2.057 & Lübnan & 1.200 & 1.200 & 1.200 & 1.200 & 1.200 \\
\hline Bosna Hersek & 1.723 & 1.720 & 1.722 & 1.722 & 1.706 & Macaristan & 1.513 & 1.503 & 1.506 & 1.509 & 1.495 \\
\hline Brezilya & 1.757 & 1.757 & 1.741 & 1.751 & 1.692 & Malezya & 1.313 & 1.312 & 1.313 & 1.313 & 1.308 \\
\hline Bulgaristan & 1.557 & 1.547 & 1.546 & 1.547 & 1.526 & Meksika & 1.739 & 1.739 & 1.734 & 1.732 & 1.725 \\
\hline Çekya & 1.807 & 1.795 & 1.791 & 1.795 & 1.754 & Misır & 1.200 & 1.114 & 1.195 & 1.200 & 1.091 \\
\hline Çin & 3.032 & 3.032 & 3.033 & 3.030 & 3.005 & Nijerya & 1.237 & 1.237 & 1.237 & 1.237 & 1.236 \\
\hline Danimarka & 3.353 & 3.357 & 3.360 & 3.356 & 1.689 & Norveç & 1.121 & 1.122 & 1.122 & 1.121 & 1.113 \\
\hline Ekvator & 1.200 & 1.200 & 1.198 & 1.198 & 1.194 & Pakistan & 1.993 & 1.990 & 1.989 & 1.995 & 1.987 \\
\hline Endonezya & 3.200 & 3.200 & 3.199 & 3.198 & 3.198 & Peru & 1.400 & 1 & 4 & 36 & 1.384 \\
\hline Ermenistan & & 1.498 & 1.500 & & 1.497 & Polonya & 1.348 & 1.342 & 1.346 & 1.350 & 1.314 \\
\hline Estonya & 1.302 & 1.299 & 1.300 & 1.300 & 1.253 & Romanya & 2.865 & 2.846 & 2.848 & 2.859 & 2.813 \\
\hline Etiyopya & 1.230 & 1.228 & 1.229 & 1.230 & 1.219 & Rusya & 3.631 & 3.625 & 3.616 & 3.625 & 3.610 \\
\hline Filipinler & 1.200 & 1.200 & 1.200 & 1.200 & 1.200 & Sirbistan & 2.534 & 2.504 & 2.475 & 2.524 & 2.363 \\
\hline Finlandiya & 1.196 & 1.194 & 1.197 & 1.189 & 1.056 & Slovakya & 1.432 & 1.427 & 1.426 & 1.426 & 1.413 \\
\hline Fransa & 1.868 & 1.864 & 1.864 & 1.866 & 1.852 & Slovenya & 1.074 & 1.072 & 1.071 & 1.067 & 1.059 \\
\hline Guatemala & 1.192 & 1.203 & 1.187 & 1.191 & 1.187 & Şili & 999 & 996 & 991 & 990 & 964 \\
\hline Güney Kore & 1.245 & 1.245 & 1.245 & 1.245 & 1.245 & Tacikistan & 1.200 & 1.198 & 1.200 & 1.200 & 1.200 \\
\hline Gürcistan & 2.193 & 2.188 & 2.192 & 2.184 & 2.162 & Tayland & 1.497 & 1.434 & 1.489 & 1.494 & 1.455 \\
\hline Hırvatistan & 1.483 & 1.483 & 1.483 & 1.485 & 1.482 & Tunus & 1.206 & 1.203 & 1.205 & 1.205 & 1.201 \\
\hline Hollanda & 2.394 & 2.392 & 2.379 & 2.378 & 663 & Türkiye & 2.415 & 2.409 & 2.404 & 2.408 & 2.378 \\
\hline Hong Kong & 2.073 & 2.072 & 2.074 & 2.074 & 2.064 & Ürdün & 1.203 & 1.199 & 1.200 & 1.203 & 1.199 \\
\hline İran & 1.499 & 1.499 & 1.499 & 1.499 & 1.496 & Vietnam & 1.200 & 1.195 & 1.200 & 1.200 & 1.191 \\
\hline İspanya & 1.209 & 1.208 & 1.199 & 1.207 & 1.196 & Yeni Zelanda & 1.031 & 1.028 & 1.038 & 1.003 & 1.014 \\
\hline İsveç & 1.192 & 1.192 & 1.190 & 1.191 & 1.189 & Yunanistan & 1.200 & 1.198 & 1.197 & 1.199 & 1.195 \\
\hline İsviçre & 3.159 & 3.174 & 3.161 & 3.160 & 3.159 & Zimbabve & 1.214 & 1.215 & 1.215 & 1.215 & 1.209 \\
\hline
\end{tabular}

\begin{tabular}{llllll}
\hline Toplam & GG: 116.606 & KG: 116.293 & N: 116.330 & E: 116.293 & P: 111.617
\end{tabular}

GG: Genel güven - Q59-63; KG: Kurumlara güven - Q68-74 ve Q77; N: Normlar - Q177-178 ve 180-181; ED: Ekonomik değer algıSı - Q106-109; PK: Politik kültür - Q241-249 (ankette kullanılan soruların kodları)

Kaynak: DDA (2020) ve ADA (2020)

Ampirik sosyal fenomenlerin nispeten sınırlı çeşitliliği nedeniyle nedensel karmaşıklık paradoksal olarak kolayca çözülemez. Deneysel olmayan durumlar arasındaki benzerlikler ve farklııklar, sosyal nedenselliği açıkça belirleme girişimlerini karıştırmaktadır (Byrne, 1998). Sosyal bilimciler, nedensel koşulların tüm farklı kombinasyonlarını sergileyen sosyal fenomenler yaratabilir ve sonra sonuçları gözlemleyebilirlerse (ki bunu deneyler yaparak 
sağlayabilirler), belirleyici nedensel kombinasyonları açıklamak basit olurdu. Bu mümkün olmadığından deneysel olmayan verilere uygun araştırma stratejileri geliştirilmektedir (Ragin, 2014). Sosyal yaşamın birçok özelliği, deneysel yöntemler kullanılamadığında nedensel karmaşıklığı çözme girişimlerini sekteye uğratmaktadır. Doğa bilimcileri, gerekli veya yeterli veya hem gerekli hem de yeterli nedenleri oluşturmaya çalışmaktadırlar. Nedenselliğin birden çok ve kombinasyon olduğu durumlarda, ilgili bir sonuç için gerekli veya yeterli koşullar olmayabilir. Bu olasılık, deneysel olmayan ortamlarda nedensel ilişkilerin gözlemlenmesini karmaşıklaştırır, çünkü araştırmacılar tipik olarak ilgili nedensel koşulların tüm mantıksal kombinasyonlarını gözlemleyemezler. Yine de karşılaştırmalı sosyal bilimciler bu tür bir nedensellik sergileyen fenomenlerle sık sık karşı karşıya kalırlar.

Geniş insan kitlelerini etkileyen koşulları manipüle etmek imkansızdır ve sosyal bilimciler, doğal olarak oluşan verileri bilime kazandırmak durumundadırlar. Yine de bu fenomenlerin nedenlerinin hem çoklu hem de kombinasyonlu olduğuna ve bu nedenle deney benzeri analizler gerektirdiğine inanmak için iyi bir neden vardır. Sadece doğal olarak oluşan veriler deneysel tasarımlara yaklaştığında bu fenomenlerde görünen karmaşık sırayı ortaya koymak mümkündür. Bu bağlamda, Ragin (1987) tarafından küme teorisi temelinde önerilen durum odaklı bir araştırma yöntemi olarak Nitel Karşılaştırmalı Analiz (NKA) kullanılmaktadır. Bu yöntem, birden çok durumun benzerlik ve farklılıklarının karşılaştırılması yoluyla koşullar ve sonuçlar arasındaki karmaşık yapılandırmayı keşfetmek için kullanılır (Ragin ve Strand, 2008). $\mathrm{Bu}$ yöntemin nitel araştırma ile nicel araştırma arasında iyi bir denge sağladığı düşünülmektedir. Diğer değişle teknik ilgiden doğan post-pozitivist ve pratik ilgiden doğan yorumlayıcı paradigmaları bir arada ele alarak pragmatik odaklı bir paradigma ortaya koymaktadır (Gunbayi ve Sorm, 2020). Bu yöntem, bir yandan durum çalışması sonuçlarının sınırlılıklarını ve tek tarafı dezavantajlarını ortadan kaldırmakta öte yandan, istatistiksel analizin tek bir bağımsız değişkenin bağımlı değişken üzerindeki marjinal net etkisi sorununu çözmektedir (Rihoux ve Ragin, 2009). NKA, yeterli ve gerekli koşulların kombinasyonunu belirleme kabiliyeti nedeniyle sosyoloji, psikoloji, yönetim ve diğer temel bilimleri kaplayan alanlarda yaygın olarak kullanılmaktadır (Antilla, 2005; Brigham, 2011; Emmenegger, Kvist ve Skaaning, 2013; Fiss, 2011; lannacci ve Cornford, 2018; Sager, Rüefli ve Thomann, 2019; Schneider, Schulze-Bentrop ve Paunescu, 2010; Vis, 2012).

\subsection{Bulanık Küme Nitel Karşılaştırmalı Analiz (bkNKA) Uygulama Adımları}

NKA'daki değerler hem net hem de bulanık olabilir ve bu çalışmada bulanık kullanılmaktadır. Net kümeler için her koşula 0 (yani, bir kümede tam üyelik yok) veya 1 (yani, bir kümede tam üyelik var) şeklinde atanır. İkinci bir NKA türü, sosyal bilimlerdeki belirsiz sınırları olan ve güvenle ikiye ayrılma olarak ifade edilemeyen kavramlar için daha uygun olan bulanık kümeler kullanır (Schneider ve Wagemann, 2012). Bu nedenle bulanık kümeler, sayısal kavramların veya verilerin detaylı olmasıyla belirlenen ek bağlantı noktaları gerektirir. Değerler, teorik bilgi, deneysel içgörüler ve verilerdeki bariz deneysel kırılmalar kullanılarak belirlenir (Ragin, 2006). Diğer deyişle bulanık küme nitel karşılaştırmalı analiz (bkNKA) araştırmasını Şekil 2'deki gibi tasarlarken araştırmacıların, nedensel koşullardaki tüm değişikliklerin yapılabilmesi için durum sayısının, nedensel koşulların ve sonucu etkileyen diğer sorunların kontrol edilmesini, ölçülmesini veya değiştirilmesini dikkatlice belirlemeleri gerekmektedir. Özellikle, koşul ve sonuç önermelerinin geliştirilmesi, bir çalışmanın karmaşık teorik beklentilerini ifade etmek için kritiktir ve resmi bkNKA tekniklerinin sonuçlarının yorumlanmasına yardımcı olur. Şekil 2 üzerinden yapılan analizin uygulamasına bakıldığında 
sonuç (inovasyon), koşullar (kurumlara güven, genel güven, normlar, ekonomik değer algısı, politik kültür) ve durum (ülkeler) ile yedi farklı sütun oluşturularak fsQCA 3.0 (Ragin, 2018) programına yerleştirilir. Bu verilerin kullanılabilir hale getirilmesi adına öncelikle hangi değerde olursa olsun 0 ve 1 arasında kalibrasyon uygulanır. Ancak kalibrasyon öncesi bulgularda belirtildiği üzere her koşulun sonuç için gerekli ve yeterli olup olmadığının test edilmesini önermekteyiz. Sonrasında Tablo 2'de yer aldığı üzere her koşula göre doğrulama tablosunda elde edilen, satırlarda yer alan kombinasyonlar oluşturulur. Bu çalışmada beş koşul olmasından ötürü 00000 ve 11111 olmak üzere $2^{5}=32$ kombinasyon oluşturulabilmektedir. Bu kombinasyonların her biri bulgularda bahsedildiği üzere iç geçerlilik testleri yapılarak geçerli olan kombinasyonlarla (çalışmada Tablo 2'deki gibi dokuz farklı kombinasyon geçerli olmaktadır) analiz kısmına geçilir. Doğrulama tablosu, koşulların bir kombinasyonunu paylaşan durum kümelerinin de sonuçlarını paylaşır. Bu kombinasyonlar, sonucun bir alt kümesi olarak yeterli olabilir. Sonuç değerinin 1 olduğu doğrulama tablosu satırları not edilir ve doğrulama tablosu satırları ile yeterli koşul kombinasyonlarını sistematik olarak karşılaştırarak program yardımıyla mantıksal minimizasyonu yapılır. Uygun basitleştirici varsayımları belirlemek adına tutarlılık eşiği ve frekans eşiği belirlenir. Net kümeler için en az 0,75 , bulanık kümeler için en az 0,8 girilebilir. Bir minimizasyon işlemine dahil edebilmesi için bir konfigürasyonun gerçekleşmesi için gereken minimum sayıda bir frekans eşiği seçilirken dikkat edilmesi gereken, çok sayıda durum (ülkeler gibi) varsa duruma göre 1'den büyük, durum sayısı azsa sadece 1 olarak girilir. Bu işlemle birlikte ortaya çıkacak Tablo 3'teki gibi uyum parametreleri olan ham tutarlılık ve kapsam gibi değerler kontrol edilir ve buna göre konfigürasyonlar gösterilerek yorumlanır.

Şekil 2: bkNKA Uygulama Süreci - 5 Değişken (Koşul)

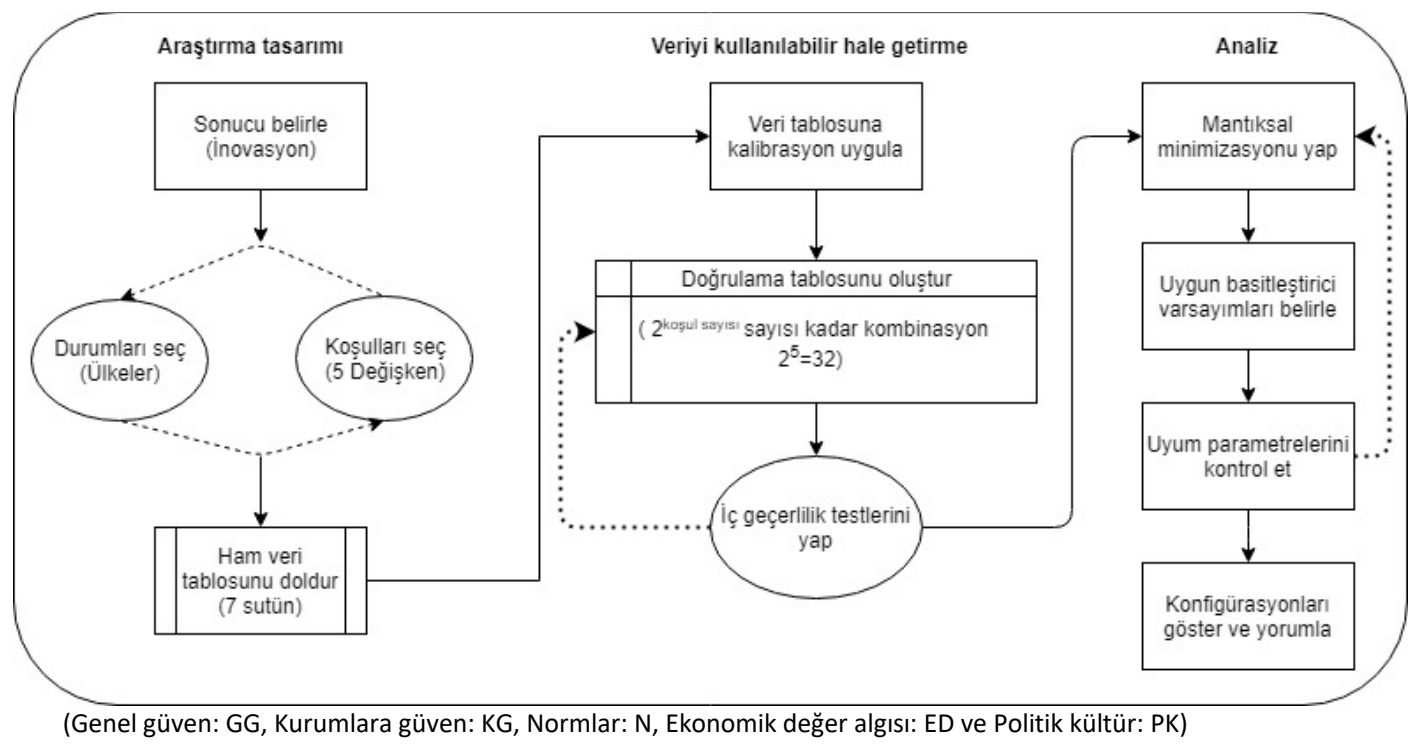




\section{Bulgular}

Şekil 2'de yer alan araştırma tasarımı sonrasında koşullara ve sonuca karşılık gelen veriler araştırmacının bilgi birikimine göre kalibre edilerek sonuç için koşulların gerekli ya da yeterli olup olmadığı değerlendirilir. Bunu yaparken de $X Y$ grafiklerinden yararlanılır. Bu grafiklerde $X$ koşulları ifade ederken, $Y$ ise sonucu belirtmektedir. NKA'da bulanık kümelerde Şekil 3'teki gibi bire yaklaşan bölgelerdeki durumların farklı yorumları vardır. Sağ alt köşedeki durumlar, koşulun sonucun bir alt kümesi olduğu argümanını ihlal ederken, sol üst köşedeki durumlar, koşulun sonucun bir üst kümesi olduğu argümanını ihlal eder.

Şekil 3: Sonuç ve Koşullara Göre XY Grafikleri

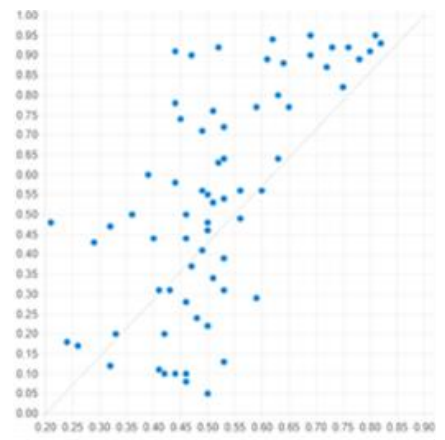

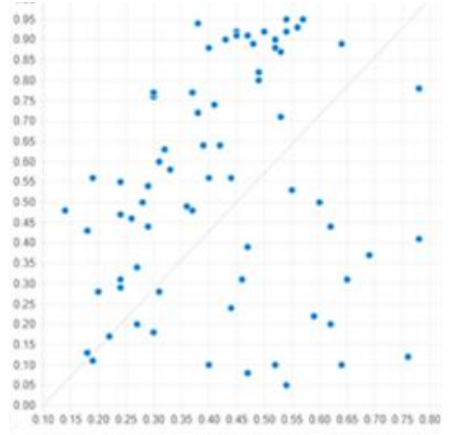

$$
\begin{gathered}
\text { Inovasyon }-\mathrm{KG} \text { : } \\
\text { Tutarlılık } \mathrm{X} \leq \mathrm{Y}: 0,807, \\
\mathrm{X} \geq \mathrm{Y}: 0,634
\end{gathered}
$$

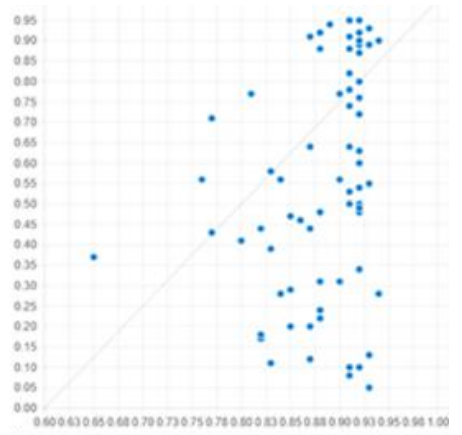

İnovasyon $-\mathrm{N}$ :

Tutarlılık $\mathrm{X} \leq \mathrm{Y}: 0,608$, $\mathrm{X} \geq \mathrm{Y}: 0,995$

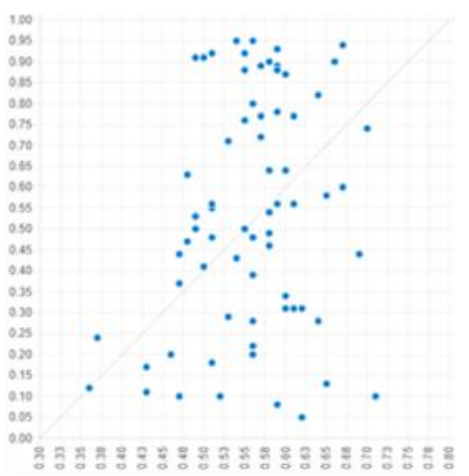

Inovasyon - ED: Tutarlılık $\mathrm{X} \leq \mathrm{Y}: 0,778$,

$\mathrm{X} \geq \mathrm{Y}: 0,804$

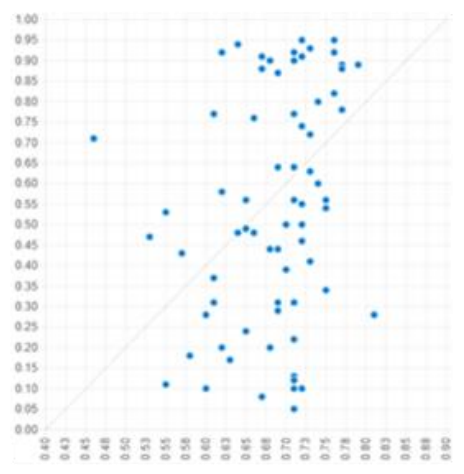

Inovasyon - PK: Tutarlılık $\mathrm{X} \leq \mathrm{Y}: 0,708$, $\mathrm{X} \geq \mathrm{Y}: 0,898$

Şekil 3'te çalışmada ele alınan beş farklı koşula karşı inovasyon sonucuna göre koşulların sonuç için gerekli ya da yeterli olup olmadığı gösterilmektedir. Burada $X \geq Y$; diğer değişle $X^{\prime}$ 'in $Y$ için gerekli olduğu tartışmasını destekleyen bir olay örgüsü olarak da görülebilir. Sağ alt bölgedeki durumlar (ülkeler), geleneksel bir nicel analizde olduğu gibi hata değildir. Daha ziyade, nedene yüksek üyeliğe sahip olmalarına rağmen, sonuca düşük üyeliğe sahip ülkelerdir. Bu örüntü, Y'nin X'in bir alt kümesi olduğunu gösterir. Y'nin oluşması için $X$ koşulu mevcut olmalıdır, ancak $X$ kendi başına Y'yi üretemeyebilir. Diğer koşullar da gerekli olabilir. Sol üst bölgedeki ülkeler ciddi hatalar olacaktır çünkü bunlar, sonuca yüksek üyelikle birlikte 
nedende düşük üyelik durumları olacaktır. $X \leq Y$ olduğunda ise (neden, sonucun bir alt kümesidir). Bu aynı zamanda $X$ 'in $Y$ için yeterli olduğu iddiasını destekleyen bir olay örgüsü olarak da görülebilir. Sol üst bölgedeki ülkeler, geleneksel bir nicel analizde olduğu gibi hata değildir. Aksine, bunlar diğer nedenlerin işleyişi nedeniyle sonuca yüksek oranda üye olan ülkelerdir. Buradaki argüman, $X^{\prime}$ 'in Y'nin bir alt kümesi olduğudur yani, $X, Y^{\prime} y i$ elde etmenin belki de birkaç yolundan biridir. Bu olay örgüsünde ise sağ alt bölgedeki ülkeler ciddi hatalar olacaktır çünkü bunlar, sonuca düşük üyelikle birlikte nedene yüksek üyelik durumları olacaktır. Bu tür ülkeler, X'in Y'nin bir alt kümesi olduğu şekilde $X$ ile $Y$ arasında açık bir bağlantı olduğu argümanını zayıflatacaktır. Bu bağlamda tutarlıı̆ı̆ı 0,8'den büyük olması koşulun sonuç için yeterli ya da gerekli olduğunu gösterir (Schneider ve Wagemann, 2012). Şekil 3 incelediğinde ise koşul olan inovasyonu açıklamak için GG'nin hem yeterli hem de gerekli, KG'nin yeterli, N’nin gerekli, ED’nin gerekli ve PK'nin gerekli olduğunu görebiliriz. Ülkeler değerleri, onların bir konfigürasyonla ilişkilendiren güçlü üyelik formudur ve bu Şekil 4'te de görselleştirilmiştir. Ülke sayı sütunu, her bir konfigürasyonla en çok ilişkili olan ülkelerin sayısını güçlü üyelik koşullarında tanımlar. Bu değerlerin incelenmesi, 9 konfigürasyonun her birinin kendileriyle ilişkili ülkeye sahip olduğunu gösterir (örneğin, konfigürasyon 11111 koşul terimiyle 7 ülke). Ülkelerin olası konfigürasyonlarda gruplandırılmasına ilişkin bu tartışma, hangi konfigürasyonların dikkate alınmaya devam edileceği açısından önemlidir. Ragin (2008) bunu bir frekans eşiği, yani bir konfigürasyonun alaka düzeyi veya uygulanabilirliği açısından tartışmaktadır.

Tablo 2: Doğrulama Tablosu

\begin{tabular}{cccccccc}
\hline GG & KG & N & ED & PK & Ülke Sayısı & Inovasyon & Ham Tutarlılık \\
\hline 1 & 0 & 1 & 1 & 1 & 22 & 1 & 0,846 \\
1 & 1 & 1 & 1 & 1 & 7 & 1 & 0,871 \\
0 & 0 & 1 & 0 & 1 & 6 & 1 & 0,823 \\
0 & 1 & 1 & 0 & 1 & 5 & 1 & 0,839 \\
0 & 1 & 1 & 1 & 1 & 5 & 1 & 0,834 \\
0 & 1 & 1 & 1 & 0 & 1 & 1 & 0,889 \\
1 & 1 & 1 & 0 & 1 & 1 & 1 & 0,879 \\
1 & 0 & 1 & 0 & 1 & 1 & 1 & 0,859 \\
0 & 0 & 1 & 1 & 1 & 14 & 0 & 0,798 \\
\hline
\end{tabular}

Doğrulama tablosunda ortaya çıkan ülkeler, Şekil 4'te Venn diyagramı ile belirtilmiştir. Buna göre 70 ülkeden Malezya, Polonya ve Tayland tek olarak farklı konfigürasyonlarda yer alırken Bulgaristan, Etiyopya, Gürcistan, Hollanda, Hong Kong, İran, Sırbistan ve Vietnam ham tutarlılığı düşük olmasından ötürü herhangi konfigürasyona girememiştir. Diğer ülkeler ve yer aldıkları konfigürasyonlar da detaylı incelenebilmektedir. Burada dikkat çeken, inovasyonun sağlanması adına diğer ülkelerde politik kültürün olması önemli iken Malezya'da politik kültürün düşük olmasına rağmen kurumlara güven, normlar ve ekonomik güven olması durumunda inovasyon gerçekleşebilmektedir. Aynı zamanda her ülkenin mutlaka normlarının yüksek olması durumu ortaya çıkmaktadır, aksi taktirde inovasyon gözlenmemektedir. 22 ülke özelinde değerlendirme yapıldığında ise bu ülkelerde kurumlara güven haricinde diğer koşulların gerçekleşmesi önemlidir. 14 ülkenin yer aldığı gruba bakıldığında ise 22 ülkedeki kurumlara güvenle birlikte genel güvenin az olduğu dikkat çekmektedir. Türkiye'nin Japonya, Bangladeş, Çin ve Azerbaycan ile yer aldığı 01111 konfigürasyonuna göre de genel güven haricinde inovasyon için gereken kurumlara güven, normlar, ekonomik değer algısı ve politik kültürdür. Romanya, Kırgızistan, G. Kore, Kolombiya, Guatemala ve Bolivya ülkelerinde ise sadece normların ve politik kültür olması inovasyon için yeterli görülmektedir. 
Şekil 4: Beş Koşullu Venn Diyagramı

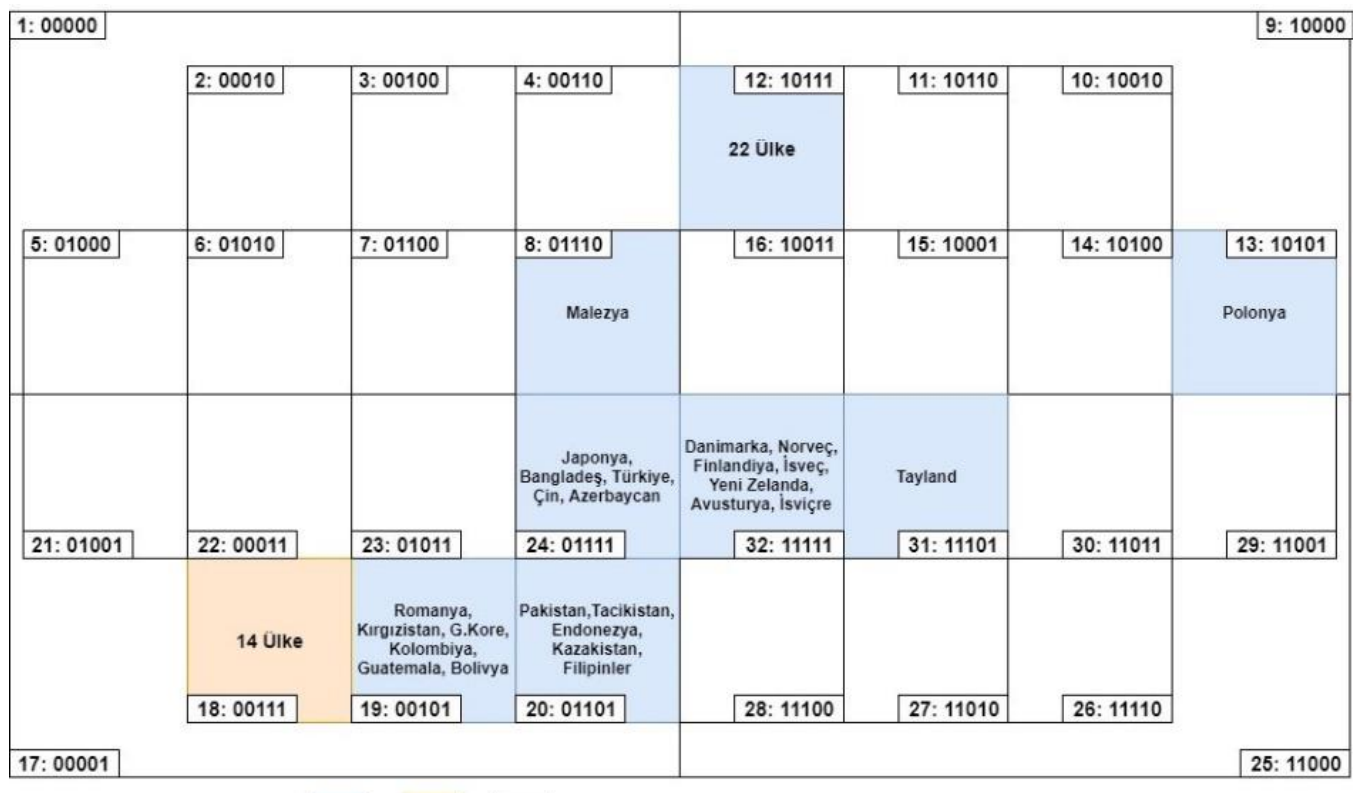

\begin{tabular}{|l|l|l|}
\hline 1 & 0 & $R$
\end{tabular}

(22 Ülke: Almanya, Mısır, Bosna Hersek, Makedonya, Estonya, İtalya, BK, Avusturalya, Slovenya, Karadağ, İzlanda, Macaristan, Hırvatistan, Ürdün, Çekya, ABD, Fransa, Litvanya, Arjantin, Slovakya, Belarus, İspanya; 14 Ülke: Ermenistan, Yunanistan, Nijerya, Kıbrıs, Zimbabve, Tunus, Peru, Brezilya, Lübnan, Arnavutluk, Şili, Ekvator, Meksika, Rusya)

Doğrulama tablosunda ve Venn diyagramıyla görselleştirilen kombinasyonlar sonrasında yapılan analiz sonucunda ortaya çıkan Tablo 3, inovasyonun gerçekleşmesi ve

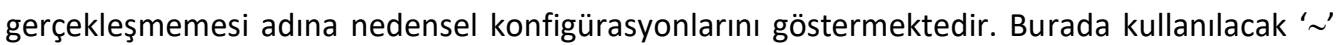
simgesi herhangi koşul ya da sonucun azlığını ifade ederken tabloda karşılığı ' $\otimes$ ' şekliyle görselleştirilmektedir. '•' ise o koşulun yüksek şekilde etkililiğinin görselleştirilmesi olarak değerlendirilebilir. Buna göre inovasyonun gerçekleşmesi için üç konfigürasyon varken gerçekleşmemesi adına iki konfigürasyon vardır. Burada yapılandırmaların uygunluğunu değerlendirmek için tutarlılık ve kapsam parametreleri önemlidir. Tutarlılık, anlamlılı̆g benzer şekilde ampirik kanıtların konfigürasyonlar ile inovasyon sonucu arasında nasıl bir ilişki olduğunu ölçer (Fiss, 2011). Her konfigürasyondaki tutarlılık ve genel çözüm tutarlılıklarına bakıldığında Ragin (2006) tarafından önerilen kesme 0,8 değerini aştığından, her konfigürasyon sonuç için yeterli olarak kabul edilebilir. Kapsam ise $R^{2 \prime}$ ye benzer şekilde, konfigürasyonların ve genel çözümün ampirik ilgisini ölçer ve böylece sonucu hangi konfigürasyonların veya bir çözümün açıkladığını gösterir (Fiss, 2011). Her bir konfigürasyonun ham kapsamı, yani her bir yöntemin sonucu ne ölçüde açıklayabildiğini gösterir. Tüm konfigürasyonlardaki ham kapsam ve çözüm kapsamları ampirik ilgilerini gösteren önerilen aralıktadır (Ragin, 2008; Woodside, 2013). Bu bilgiler ışığında inovasyonun gerçekleşmesi adına ilk nedensel konfigürasyon normlar* ^ekonomik değer algısı*politik kültür şeklinde ifade edilirken genel olarak ülkelerde normların ve politik kültürün yüksek olması durumunda ekonomik değer algısının düşük olmasına rağmen inovasyona olumlu yansıması olduğunu ortaya koymaktadır. Bu konfigürasyonda; Tacikistan, Kırgızistan, Bolivya, Guatemala, Endonezya, Pakistan, Kazakistan, Filipinler, Polonya, Kolombiya, Romanya, Tayland ve Güney 
Kore gibi ülkelerin olduğu gözlenmektedir. İkinci nedensel konfigürasyona bakıldığında ise genel güven*normlar*politik kültür; bize bir ülkede aynı anda genel güven, normlar, politik kültür yüksekse bu ülkede inovasyon gözlenmesi olası olduğunu göstermektedir. Buradaki ülkeler ise; Norveç, Finlandiya, İzlanda, Danimarka, Hollanda, İsveç, BK, Yeni Zelanda, İsviçre, Avusturya, İspanya, Fransa, Avusturalya, Estonya, Macaristan, ABD, Almanya, Hırvatistan, Çekya ve en sonunda Arjantin olarak karşımıza çıkmaktadır. İnovasyonun gerçekleşmesi için gereken son nedensel konfigürasyona bakıldığında ise genel güven*kurumlara güven*normlar*ekonomik değer algısı şeklinde ifade edilirken bu ülkelerde genel güvenin düşük olmasına rağmen kurumlara güvenin, normların ve ekonomik değer algısının yüksek olması durumunda ülkede inovasyonun gözlenme olasılığını belirtmektedir. Burada yer alan ülkeler; Azerbaycan, Bangladeş, Çin, Türkiye, Japonya ve Malezya olarak gözlenmektedir.

Tablo 3: İnovasyon İçin Koşulların Yeterli Konfigürasyonları

\begin{tabular}{|c|c|c|c|c|c|}
\hline & \multicolumn{5}{|c|}{ Nedensel Konfigürasyon (Sonuç) } \\
\hline & \multicolumn{3}{|c|}{ İnovasyon } & \multicolumn{2}{|c|}{ innovasyon } \\
\hline & 1 & 2 & 3 & 1 & 2 \\
\hline Genel Güven & & $\bullet$ & $\otimes$ & $\otimes$ & $\otimes$ \\
\hline Kurumlara Güven & & & $\bullet$ & & $\bullet$ \\
\hline Normlar & $\bullet$ & $\bullet$ & $\bullet$ & $\bullet$ & $\bullet$ \\
\hline Ekonomik Değer Algısı & $\otimes$ & & $\bullet$ & $\otimes$ & $\bullet$ \\
\hline Politik Kültür & $\bullet$ & $\bullet$ & & $\bullet$ & $\otimes$ \\
\hline Tutarlılık & 0,807 & 0,845 & 0,835 & 0,820 & 0,829 \\
\hline Ham Kapsam & 0,660 & 0,801 & 0,541 & 0,725 & 0,509 \\
\hline Çözüm Kapsamı & & 0,827 & & & \\
\hline Çözüm Tutarlılığı & & 0,803 & & & \\
\hline
\end{tabular}

Diğer yandan inovasyonun gerçekleşmeme durumunu ele alacak olursak ilk konfigürasyon genel güven*normlar* ekonomik değer algısı*politik kültür şeklinde ifade edilirken ülkede normların ve politik kültürün yüksek olmasına rağmen şayet aynı anda hem genel güven hem de ekonomik değer algısı düşük ise ülkede inovasyonun gerçekleşmesinin zor olduğunu belirtmektedir. Burada yer alan ülkeler Tacikistan, Bolivya, Guatemala, Endonezya, Pakistan, Kazakistan, Filipinler, Kırgızistan, Kolombiya, Romanya ve Güney Kore'dir. Diğer nedensel konfigürasyon genel güven*kurumlara güven*normlar*ekonomik değer algısı* politik kültür ise kurumlara güvenin, normların ve ekonomik değer algısının yüksek olmasına rağmen şayet ülkede hem genel güven hem de politik kültür düşük ise o ülkede diğerlerin varlığına rağmen inovasyonun gerçekleşmesinin zorluğunu ifade etmektedir. Burada yer alan tek ülke Malezya'dır. Genel olarak değerlendirildiğinde, her koşulun azlığı ve çokluğunun inovasyonda asimetrik bir etki yarattığı gözlenmektedir. Analizler sonrasında ülkeler özelinde ortaya çıkan bu son konfigürasyonların hepsi Ek-1'de özetlenmektir.

\section{Sonuç}

Bu çalışmada karmaşık uyarlanabilir sistem (CAS) yaklaşımından yola çıkarak 70 ülkeden 116.606 kişiden toplanan Dünya Değerler Anketi (DDA) ve Avrupa Değerler Anketi (ADA)'nde yer alan sosyal sermayenin kapsadığı genel güven, kurumlara güven, normlar ile ekonomik değer algısı ve politik kültür ile Küresel İnovasyon Endeksi (KiE)'ndeki ülkelerin inovasyon 
verilerinden yararlanarak koşullar ve sonuç arasında nedensel bir ilişki incelemesi bulanık küme nitel karşılaştırmalı analiz (bkNKA) yardımıyla yapılmıştır.

İnovasyonun, tüm analize giren ülkelerin genel değerlendirmesine göre, gerçekleşmesine bakıldığında koşullardan herhangi ikisinin aynı anda az olması inovasyonun gerçekleşmesine engel olmaktadır. Özellikle ülkelerde oluşan pozitif normlar ve politik kültürün yüksek olması bir anlamda inovasyonu olumlu etkilemektedir. Ekonomik değer algısı ve genel güvenin tek başına farklı konfigürasyonlarda az olmasının olumsuz bir tarafı olmazken, aynı anda ikisinin azlığında inovasyon gerçekleşmesi güçleşmektedir. Yine aynı şekilde genel güven ve politik kültürün de aynı anda azlığında inovasyonun gerçekleşmesi güçleşirken, bu durumda kurumlara güvenin, normların ve ekonomik değer algısının yüksek olmasının çok fazla etkisi olmamaktadır. Ülkeler özelinde bir değerlendirme yapıldığında Tacikistan, Kırgızistan, Bolivya, Guatemala, Endonezya, Pakistan, Kazakistan, Filipinler, Polonya, Kolombiya, Romanya, Tayland ve Güney Kore ülkelerinde genel güven ve kurumlara güvenin olup olmamasından bağımsız olarak aslında ekonomik değer algısının düşük olmasının yanı sıra politik kültürün güçlü olduğunda ve normların olumlu olduğunda bir şekilde inovasyonda başarılı olması olasıdır. Bu ülkelere bakıldığında ise hepsinin de güç mesafesinin yüksek olduğu ülkeler arasında olduğunu söyleyebiliriz (Hofstede, Hofstede ve Minkov, 2010). Norveç, Finlandiya, İzlanda, Danimarka, Hollanda, İsveç, BK, Yeni Zelanda, İsviçre, Avusturya, İspanya, Fransa, Avusturalya, Estonya, Macaristan, ABD, Almanya, Hırvatistan, Çekya ve Arjantin ülkelerinde kurumlara güven ve ekonomik değer algısından bağımsız olarak genel güven, normlar ve politik kültürün güçlü olması koşulunda inovasyonun gerçekleşmesi olasıdır. Bu ülkelere bakıldığında Hırvatistan haricinde Hofstede vd. (2010)'un ortaya koyduğu bireyci kültürler olduğuna dikkat etmekte yarar var. Diğer yandan Arjantin özelinde ele aldığımızda ise güç mesafesinin az olmasına rağmen az da olsa kolektivist bir yapısını olduğunu söyleyebiliriz.

Azerbaycan, Bangladeş, Çin, Türkiye, Japonya ve Malezya ülkelerine bakıldığında ise politik kültüründen bağımsız olarak genel güvenin az olmasına rağmen kurumlara güven, normlar ve ekonomik değer algısının güçlü olması koşuluyla inovasyon gerçekleşme olasılığı yüksektir. Bu ülkeler özelinde ise hepsinin hem güç mesafesinde yüksek hem de kolektivist bir yapıda olması (Hofstede vd., 2010) bu koşulların nedensel açıklamasında yararlı olduğu düşünülebilir. Diğer yandan kurumlara güvenden bağımsız olarak genel güven ve ekonomik değer algısının düşük, normlar ve politik kültürün güçlü olmasına rağmen Tacikistan, Bolivya, Guatemala, Endonezya, Pakistan, Kazakistan, Filipinler, Kırgızistan, Kolombiya, Romanya ve Güney Kore ülkelerinde bu koşullarda inovasyon gözlenmesi olası görünmemektedir. Bu ülkelere dikkatli bakıldığında ise belirsizlikten kaçınmanın yüksek olduğu ve kolektivist bir yapıda olduğu gözlenmektedir (Hofstede vd., 2010). Bu anlamda belirsizlik ne kadar çoksa inovasyondan kaçınma gözlenmektedir (Shane, Venkataraman ve MacMillan, 1995). Aynı şekilde genel güven ve politik kültürün düşük olması ile kurumlara güven, normlar ve ekonomik değer algısının yüksek olmasına rağmen Malezya gibi ülkelerde inovasyon ortaya çıkması zor gibi değerlendirilebilir. Zayıf belirsizlikten kaçınma kültürlerinin temel yeniliklerde daha iyi olduğu doğru olabilir, ancak bu yenilikleri yeni ürünlere veya hizmetlere dönüştürmede dezavantajlı görünmektedirler.

$\mathrm{Bu}$ anlamda sosyal sermaye ve inovasyon arasındaki ilişkisel veya betimsel çalışmalar (Brockman vd., 2018; Cáceres-Carrasco vd., 2020; Cho, 2018; Dakhli ve De Clercq, 2004; Doh ve Ács, 2009; Ghazinoory vd., 2014; Knack ve Keefer, 1997; Putnam, 1993), ekonomik değer algısı ve inovasyon arasındaki ilişkisel veya betimsel çalışmalar (Beugelsdijk, 2010; Diwan vd., 
2018; Gorodnichenko ve Roland, 2011), politik kültür ve inovasyon arasındaki ilişkisel veya betimsel çalışmalar (Arnstein, 1969; Hausmann ve Rodrik, 2003; Kroll, 2017; Pfotenhauer vd., 2016; van der Molen vd., 2019) bizlere nedensellik konusunda bir gösterge sunamazken bkNKA ile yapılan çalışmaların böyle bir iddiasının olmasının (Ragin, 1987, 2008, 2014; Rihoux ve Ragin, 2009) aslında asimetrik analizlerin gücünü de bizlere göstermektedir. Gelecekte yapılacak çalışmaların bu pragmatik bakış açısını değerlendirerek asimetrik analizleri hemen hemen her alanda yapılan çalışmalar (Antilla, 2005; Brigham, 2011; Emmenegger vd., 2013; Fiss, 2011; lannacci ve Cornford, 2018; Sager vd., 2019; Schneider vd., 2010; Vis, 2012) gibi değerlendirmesi bilimsel çalışmaların geleceği için de oldukça önemli olduğunu düşünüyoruz.

Son yıllarda, gelişmekte olan ülkeler de dahil olmak üzere inovasyonu teşvik etmeye yönelik siyasi kararlılık güçlü olmuştur. Bu, yalnızca belirli sayıdaki üst düzey ekonomi ve kümelenmelerin ötesinde yeniliği demokratikleştirmeye yönelik nispeten yeni ve umut verici bir eğilimdir. COVID-19 krizi gibi karmaşık durumlarda turizm, eğitim ve perakende gibi birçok geleneksel sektörde de inovasyonu destekleyebilir. Şirketlerde ve bireysel düzeyde işin nasıl organize edildiği ve üretimin yerel ve küresel olarak nasıl organize edildiği konusunda bireylerin değişimiyle birlikte inovasyon tetiklenebilir. Daha iyi çözümlerin ortaya çıkması ve kök salması için uzun vadeli stratejiler çok önemlidir. Özellikle inovatif yaklaşımlara ve pilot projelere öncülük eden yerel yönetimler bunu tesadüfen yapmıyor. Çoğu durumda, arkasında uzun bir deneme yanılma geçmişi vardır. Şehirler, yerel kimliklerinin ve tarihlerinin sürekli analizine dayanan bir sürdürülebilirlik ve dönüşüm kültürü geliştirme konusunda sabırlı olmalıdır. Pek çok kalkınma zorluğunun karşılanmasında önemli ilerleme sağlanmıştır. Geçtiğimiz kuşak içinde yüz milyonlarca insan aşırı yoksulluktan çıktı ve eşit eğitime erişim büyük ölçüde artmıştır. Tıp ve enerji gibi çeşitli alanlarda bilimsel ve teknolojik inovasyonun yaptığı gibi bilgi ve iletişim teknolojisinin yayılması, insan gelişimini hızlandırmak, dijital uçurumu kapatmak ve bilgi toplumlarını geliştirmek için büyük bir potansiyele sahiptir. Bu bağlam çalışmanın sonuçlarıyla ele alındığında, inovasyon gibi karmaşık uyarlanabilir bir sistem için ülkeler özelinde tek bir nedensellik durumu olmadığı söylenebilir. Her ülkenin bulunduğu coğrafya, toplum yapısı, normları, algıları, politik kültürü gibi inovasyonu doğuran farklı bileşenlerinin olduğu ortaya konulabilir. Örneğin; ABD, BK, Almanya, Fransa, Hollanda, Finlandiya gibi bireyci ülkelerde genel güvenin yüksek olması inovasyonda önemli etkisi varken Türkiye, Azerbaycan, Çin, Japonya ve Malezya gibi kolektivist ülkelerde genel güvenin düşük olmasına rağmen kurumlara güven yüksekse inovasyon gözlenmektedir.

Çalışmanın sınırıııklarına bakıldığında, elde edebileceğimiz ayrıntı düzeyinde bizi kısıtlayan verilerin karşılaştırılabilmesi adına 70 ülke üzerinde bir çalışma yaptık ve bu ülkelerden sekizi doğrulama tablosunda elenerek analize dahi giremedi. Sonuç olarak, araştırmamız daha çok koşulların varlığına ve sonucun kendisine odaklandı. Gelecekteki araştırmalar, bu mekanizmaları daha doğrudan, örneğin boylamsal araştırma veya süreç izleme yoluyla ele almalıdır. Örneğin bu çalışmada olduğu gibi kesitsel yerine 20 yıllık boylamsal verilerden yararlanılması da fayda sağlayacaktır. 


\section{Kaynaklar}

Ada, E. V. S. (2020). "EVS 2017 - European Values Study 2017: Integrated Dataset". https://doi.org/10.4232/1.13511

Antilla, L. (2005), "Climate of Scepticism: US Newspaper Coverage of The Science of Climate Change", Global Environmental Change, Vol. 15, No. 4: 338-352.

Arnstein, S. R. (1969), "A Ladder of Citizen Participation", Journal of the American Planning Association, Vol. 35, No. 4: 216-224.

Beugelsdijk, S. (2010), "Entrepreneurial Culture, Regional Innovativeness and Economic Growth", Entrepreneurship and Culture, Berlin Heidelberg: Springer: 129-154.

Brigham, A. M. (2011), "Agricultural Exports and Food Insecurity in Sub-Saharan Africa: A Qualititative Configurational Analysis", Development Policy Review, Vol. 29, No. 6: 729-748.

Brockman, P.; Khurana, I. K.; Zhong, R. (2018), "Societal Trust And Open Innovation", Research Policy, Vol. 47, No. 10: 2048-2065.

Byrne, D. (1998), Complexity Theory and the Social Science, New York, NY: Routledge.

Byrne, D. (2013), "Evaluating Complex Social Interventions in A Complex World", Evaluation, Vol. 19, No. 3: 217-228.

Cáceres-Carrasco, F. R.; Santos, F. J.; Guzmán, C. (2020), "Social Capital, Personal Values and Economic Development: Effect On Innovation. An International Analysis", Innovation: The European Journal of Social Science Research, Vol. 33, No. 1: 70-95.

Cho, S.-Y. (2018), Social Capital and Innovation: Can Social Trust Explain The Technological Innovation of The High-Performing East Asian Economies? MAGKS Joint Discussion Paper Series in Economics (No. 30-2018). Marburg.

Christian, D. (2016), Big History, London: Penguin Random House.

Christian, D. (2018), Origin Story: A Big History of Everything, New York, NY: Little, Brown Spark.

Connoly, W. E. (2013), The Fragility of Things: Self Organising Processes, Neoliberal Fantasies, and Democratic Activisim, Durham and London: Duke University Press.

Dakhli, M.; De Clercq, D. (2004). "Human Capital, Social Capital, and Innovation: A Multi-Country Study", Entrepreneurship \& Regional Development, Vol. 16, No. 2: 107-128.

DDA (2020), World Values Survey, (Ed. Haerpfer, C.; Inglehart, R.; Moreno, A.; Welzel, C.; Kizilova, K.; Diez-Medrano J.; M. Lagos, P; Norris, E. et al.) - Country-Pooled Datafile. Madrid, Spain \& Vienna, Austria: JD Systems Institute \& WVSA Secretariat.

Diwan, I.; Tzannatos, Z.; Akin, T. (2018). "Debunking Myth: Economic Values in The Arab World Through The Prism of Opinion Polls", Middle East Development Journal, Vol. 10, No. 1: 31-63.

Doh, S.; Ács, Z. J. (2009). "Innovation and Social Capital: Across-Country Investigation", Jena Economic Research Papers, Friedrich Schiller University Jena and Max Planck Institute of Economics, Jena, No.2009,82.

Emmenegger, P.; Kvist, J.; Skaaning, S.-E. (2013), "Applications in Comparative Welfare-State Research Making The Comparative of QCA", Political Research Quarterly, Vol. 66, No. 1: 185-190.

Fiss, P. C. (2011), "Building Better Causal Theories: A Fuzzy Set Approach to Typologies in Organization Research", Academy of Management Journal, Vol. 54, No. 2: 393-420.

Fungáčová, Z.; Hasan, I.; Weill, L. (2019), "Trust in Banks", Journal of Economic Behavior and Organization, Vol. 157: 452-476.

Fungáčová, Z.; Weill, L. (2018). "Trusting Banks in China”, Pacific Economic Review, Vol. 23, No. 2: 131-149. 
Gabel, M.; Whitten, G. D. (1997), "Economic Conditions, Economic Perceptions, and Public Support For European İntegration", Political Behavior, Vol. 19, No. 1: 81-96.

Ghazinoory, S.; Bitaab, A.; Lohrasbi, A. (2014), "Social Capital and National İnnovation System: A Cross-Country Analysis", Cross Cultural Management, Vol. 21, No. 4: 453-475.

Gorodnichenko, Y.; Roland, G. (2011), "Which Dimensions of Culture Matter For Long-Run Growth? American Economic Review, Vol. 101, No. 3: 492-498.

Gunbayi, I.; Sorm, S. (2020), Social Paradigms in Guiding Management Social Development And Social Research, Ankara: Pegem Academy.

Hansford, T. G.; Gomez, B. T. (2015), "Reevaluating The Sociotropic Economic Voting Hypothesis", Electoral Studies, Vol. 39: 15-25.

Hardin, R. (2002), Trust and Trustworthiness: A Volume in The Russell Sage Foundation Series on Trust, New York: Russell Sage Foundation.

Hausmann, R.; Rodrik, D. (2003), "Economic Development as Self-Discovery", Journal of Development Economics, Vol. 72, No. 2: 603-633.

Hofstede, G.; Hofstede, G. J.; Minkov, M. (2010), Cultures and Organizations: Software of The Mind (Rev. $3^{\text {rd }}$ ), New York, NY: McGraw-Hill.

Holland, J. H. (2012), Signals and Boundaries: Building Blocks for Complex Adaptive Systems, London: MIT Press.

Holland, J. H. (2014), Complexity: A Very Short Introduction, Oxford: Oxford University Press.

lannacci, F.; Cornford, T. (2018), "Unravelling Causal and Temporal Influences Underpinning Monitoring Systems Success: A Typological Approach", Information Systems Journal, Vol. 28, No. 2: 384407.

Keeley, B. (2007), Human Capital: How What You Know Shapes Your Life, OECD Insights, Paris: OECD Publishing.

Kenny, J. (2018), "The Role of Economic Perceptions in Influencing Views on Climate Change: An Experimental Analysis With British Respondents", Climate Policy, Vol. 18, No. 5: 581-592.

KiE (2020), The Global Innovation Index 2020: Who Will Finance Innovation? Ithaca, Fontainebleau and Geneva: Cornell University, INSEAD, WIPO.

Knack, S.; Keefer, P. (1997), "Does Social Capital Have an Economic Payoff? A Cross-Country Investigation", The Quarterly Journal of Economics, Vol. 112, No. 4: 1251-1288.

Kołczyńska, M. (2020), "Democratic Values, Education, and Political Trust", International Journal of Comparative Sociology, Vol. 61, No. 1: 3-26.

Kroll, H. (2017), "Smart Specialization Policy in an Economically Well-Developed, Multilevel Governance System", (Ed. S. Radosevic; A. Curaj; R. Gheorghiu; L. Andreescu; I. Wade), Advances in the Theory and Practice of Smart Specialization, Academic Press: 99-123

Lewis-Beck, M. S.; Nadeau, R.; Elias, A. (2008), "Economics, Party, and The Vote: Causality Issues and Panel Data", American Journal of Political Science, Vol. 52, No.1: 84-95.

Marsh, R. M. (2009), "How Similar are The Values of The People of China and Taiwan?", Comparative Sociology, Vol. 8, No. 1: 39-75.

Mas-Tur, A.; Guijarro, M.; Carrilero, A. (2020), "What Type of Entrepreneurship Leads to Sustainable Development? A Configurational Approach", Social Indicators Research: 1-14.

Miller, J. H.; Page, S. E. (2007), Complex Adaptive Systems: An Introduction to Computational Models of Social Life, New Jersey: Princeton University Press.

Newton, K. (1997), "Social Capital and Democracy", American Behavioral Scientist, Vol. 40, No. 5: 575-586. 
OECD. (2001a), The New Economy: Beyond The Hype, Paris: OECD.

OECD. (2001b), The Well-Being of Nations: The Role of Human and Social Capital, Paris: OECD.

Ostrom, E. (2015), Governing The Commons: The Evolution of Institutions for Collective Action, Cambridge: Cambridge University Press.

Park, J. Y. (2019), "Punishing Without Rewards? A Comprehensive Examination of The Asymmetry in Economic Voting", Electoral Studies, Vol.57: 1-18.

Pfotenhauer, S. M.; Wood, D.; Roos, D.; Newman, D. (2016), "Architecting Complex International Science, Technology and Innovation Partnerships (Cistıps): A Study of Four Global MIT Collaborations", Technological Forecasting and Social Change, Vol. 104: 38-56.

Putnam, R. (1993), "The Prosperous Community: Social Capital and Public Life", The American Prospect, Vol. 4, No. 13: 35-42.

Pye, L. W. (1968). "Political Culture". In D. L. Sills (Ed.), Encyclopedia of The Social Sciences. New York, NY: Macmillan: 218-224.

Ragin, C. C. (1987), The Comparative Method: Moving Beyond Qualitative and Quantitative Strategies, Berkeley: University of California Press.

Ragin, C. C. (2006), "Set Relations in Social Research: Evaluating Their Consistency and Coverage", Political Analysis, Vol. 14, No. 3: 291-310.

Ragin, C. C. (2008), Redesigning Social Inquiry: Fuzzy Sets and Beyond, Chicago: University of Chicago Press.

Ragin, C. C. (2014), The Comparative Method: Moving Beyond Qualitative and Quantitative Strategies With A New Introduction, California: University of California Press.

Ragin, C. C. (2018), User's Guide to Fuzzy-Set/Qualitative Comparative Analysis 3.0, Irvine, California: Department of Sociology, University of California.

Ragin, C. C.; Strand, S. I. (2008), "Using Qualitative Comparative Analysis to Study Causal Order: Comment on Caren and Panofsky (2005)", Sociological Methods \& Research, Vol. 36, No. 4: 431-441.

Rihoux, B.; Ragin, C. C. (2009), Configurational Comparative Methods. Qualitative Comparative Analysis (QCA) and Related Techniques, California: Sage.

Robbins, S. P.; Judge, T. A. (2017), Organizational Behavior, Essex: Pearson Education.

Rogers, E. M. (2003), Diffusion of Innovations, $5^{\text {th }}$ Ed., New York, NY: Free Press.

Sager, F.; Rüefli, C.; Thomann, E. (2019), "Fixing Federal Faults. Complementary Member State Policies in Swiss Health Care Policy", International Review of Public Policy, Vol. 1, No. 2: 147-172.

Salehan, M.; Kim, D. J.; Lee, J. N. (2018), "Are There Any Relationships Between Technology And Cultural Values? A Country-Level Trend Study of The Association Between Information Communication Technology and Cultural Values", Information and Management, Vol. 55, No.6: 725-745.

Schneider, C. Q.; Wagemann, C. (2012), Set-Theoretic Methods for The Social Sciences: A Guide to Qualitative Comparative Analysis, Cambridge: Cambridge University Press.

Schneider, M. R.; Schulze-Bentrop, C.; Paunescu, M. (2010), "Mapping The Institutional Capital of High-Tech Firms: A Fuzzy-Set Analysis of Capitalist Variety and Export Performance", Journal of International Business Studies, Vol. 41, No. 2: 246-266.

Shane, S.; Venkataraman, S.; MacMillan, I. (1995), "Cultural Differences in Innovation Championing Strategies", Journal of Management, Vol. 21, No. 5: 931-952.

Tilley, J.; Garry, J.; Bold, T. (2008), "Perceptions and Reality: Economic Voting at The 2004 European Parliament Elections", European Journal of Political Research, Vol. 47, No. 5: 665-686.

Turner, F. C.; Elordi, C. A. (1995), "Economic Values and The Role of Goverment in Latin America", International Social Science Journal, Vol. 145: 473-488. 
Van der Molen, F.; Ludwig, D.; Consoli, L.; Zwart, H. (2019). “Global Challenges, Dutch Solutions? The Shape of Responsibility in Dutch Science and Technology Policies", Journal of Responsible Innovation, Vol. 6, No. 3: 340-345.

Vis, B. (2012), "The Comparative Advantages of FsQCA and Regression Analysis for Moderately Large-N Analyses", Sociological Methods \& Research, Vol. 41, No. 1: 168-198.

Wang, X.; Wang, Z.; Jiang, Z. (2020), "Configurational Differences of National Innovation Capability: A Fuzzy Set Qualitative Comparative Analysis Approach", Technology Analysis \& Strategic Management, 1-13.

Weakliem, D. L.; Andersen, R.; Heath, A. F. (2005), “By Popular Demand: The Effect of Public Opinion on Income Inequality", Comparative Sociology, Vol. 4, No. 3-4: 261-284.

Williams, A. (2020), Political Hegemony and Social Complexity, Cham: Springer International Publishing.

Woodside, A. G. (2013), "Moving Beyond Multiple Regression Analysis to Algorithms: Calling for Adoption of A Paradigm Shift from Symmetric to Asymmetric Thinking in Data Analysis and Crafting Theory", Journal of Business Research, Vol. 66, No. 4: 463-472. 
Eskişehir Osmangazi Üniversitesi İktisadi ve İdari Bilimler Fakültesi Dergisi

EK-1: Inovasyon Iç̧in Koşulların Ülkelere Göre Yeterli Konfigürasyonları

\begin{tabular}{|c|c|c|c|c|c|}
\hline & & rasyon & & นinovasyon & \\
\hline & 1 & 2 & 3 & 1 & 2 \\
\hline Genel Güven & & - & $\otimes$ & $\otimes$ & $\otimes$ \\
\hline Kurumlara Güven & & & - & & - \\
\hline Normlar & - & - & - & - & - \\
\hline Ekonomik Değer Algısı & $\otimes$ & & - & $\otimes$ & $\bullet$ \\
\hline Politik Kültür & - & - & & - & $\otimes$ \\
\hline ABD & & $\mathrm{v}$ & & & \\
\hline Almanya & & $\mathrm{v}$ & & & \\
\hline Arjantin & & $\mathrm{v}$ & & & \\
\hline Avusturalya & & $v$ & & & \\
\hline Avusturya & & $\mathrm{v}$ & & & \\
\hline Azerbaycan & & & $\mathrm{v}$ & & \\
\hline Bangladeş & & & $\mathrm{v}$ & & \\
\hline Birleşik Krallık & & $\mathrm{v}$ & & & \\
\hline Bolivya & $v$ & & & $v$ & \\
\hline Çekya & & $\mathrm{v}$ & & & \\
\hline Çin & & & $\mathrm{v}$ & & \\
\hline Danimarka & & $\mathrm{v}$ & & & \\
\hline Endonezya & $v$ & & & $v$ & \\
\hline Estonya & & $\mathrm{v}$ & & & \\
\hline Filipinler & $v$ & & & $\mathrm{v}$ & \\
\hline Finlandiya & & $v$ & & & \\
\hline Fransa & & $\mathrm{v}$ & & & \\
\hline Guatemala & $v$ & & & $v$ & \\
\hline Güney Kore & $v$ & & & $\mathrm{v}$ & \\
\hline Hırvatistan & & $\mathrm{v}$ & & & \\
\hline Hollanda & & $\mathrm{v}$ & & & \\
\hline İspanya & & $\mathrm{v}$ & & & \\
\hline İsveç & & $\mathrm{v}$ & & & \\
\hline İsviçre & & $v$ & & & \\
\hline İzlanda & & $\mathrm{v}$ & & & \\
\hline Japonya & & & $v$ & & \\
\hline Kazakistan & $v$ & & & $\mathrm{v}$ & \\
\hline Kırgızistan & $v$ & & & $\mathrm{v}$ & \\
\hline Kolombiya & $v$ & & & $v$ & \\
\hline Macaristan & & $\mathrm{v}$ & & & \\
\hline Malezya & & & $\mathrm{v}$ & & $\mathrm{v}$ \\
\hline Norveç & & $v$ & & & \\
\hline Pakistan & $v$ & & & $\mathrm{v}$ & \\
\hline Polonya & $v$ & & & $v$ & \\
\hline Romanya & $v$ & & & $v$ & \\
\hline Tacikistan & $v$ & & & $v$ & \\
\hline Tayland & $v$ & & & & \\
\hline Türkiye & & & $v$ & & \\
\hline Yeni Zelanda & & $v$ & & & \\
\hline
\end{tabular}




\section{Extended Summary}

\section{Complex Relationship of Countries' Innovation Level with Social Capital, Economic Value Perception and Political Culture: Fuzzy-Set Qualitative Comparative Analysis}

While the pace of innovation has increased exponentially in the last 500 years, trade and capitalism have become increasingly effective drivers of innovation and have been linked to shedding light on today's world (Christian, 2018). The complex adaptive systems (CAS) idea suggests that all components in any system interact and connect with each other in unpredictable and unplanned ways (Holland, 2012). The components mentioned here actually turn into structures that learn and adapt in the face of their interactions with other components. In this sense, social capital (general trust, trust in institutions, norms), economic value perception and political culture associated with innovation are evaluated as components that interact with each other.

In the study, based on the CAS approach, in order to reveal such a causality relationship, the connection between the countries' social capital, economic value perception and political culture and the innovation level was examined with a CAS perspective and fuzzy-set qualitative comparative analysis (fsQCA) method. From this pragmatic point of view, searching for a causal relationship between these conditions (general trust, trust in institutions, norms, economic value perception and political culture) and outcome (innovation) reveals the originality of the study. Secondary data from the World Values Survey, the European Values Survey, and the Global Innovation Index were used in the study.

When we look at the realization of innovation, according to the general evaluation of all countries included in the analysis, the fact that any two of the conditions are less at the same time prevents the innovation from taking place. In a sense, positive norms and high political culture in countries positively affect innovation. While economic value perception and general trust are low alone in different configurations does not have a negative side, it becomes difficult to realize innovation in the absence of both at the same time. Likewise, the low level of general trust and political culture at the same time become innovation difficult, and in this case, trust in institutions, norms and high economic value perception do not have much effect.

When a country-specific assessment is made, it is seen that cultural differences come to the fore as a defining feature. For example, in Tajikistan, Kyrgyzstan, Bolivia, Guatemala, Indonesia, Pakistan, Kazakhstan, the Philippines, Poland, Colombia, Romania, Thailand, and South Korea, regardless of whether there is general trust and trust in institutions, it is possible that, in fact, economic value is low, as well as when the political culture is strong and the $\mathrm{N}$ are positive, somehow it perception is likely to be successful in innovation. Looking at these countries, we can say that all of them are among the countries with high power distance (Hofstede, Hofstede, \& Minkov, 2010). Innovation is likely to happen if the general trust, norms and political culture are strong in Norway, Finland, Iceland, Denmark, Netherlands, Sweden, UK, New Zealand, Switzerland, Austria, Spain, France, Australia, Estonia, Hungary, USA, Germany, Croatia, Czechia and Argentina, regardless of trust in institutions and economic value perception. Countries in this cluster, with the exception of Croatia, are seen as individualistic cultures (Hofstede et al., 2010).

On the other hand, when we consider it specifically for Argentina, we can say that it has a collectivist structure, albeit a little, despite its low power distance. In Azerbaijan, Bangladesh, China, Turkey, Japan, Malaysia; regardless of the political culture and despite the low general trust, innovation is likely to occur when trust in institutions, norms and economic value perception are strong. Specific to these countries, the fact that all of them are both high in power distance and collectivist (Hofstede et al., 2010) can be thought to be useful in the causal explanation of these conditions. On the other hand, regardless of trust in institutions, despite the low perception of general trust and economic value, and strong norms and political culture, it seems unlikely that innovation will be observed in Tajikistan, Bolivia, Guatemala, Indonesia, Pakistan, Kazakhstan, Philippines, Kyrgyzstan, Colombia, Romania and South Korea under these conditions. When these countries are examined carefully, it has been found that uncertainty avoidance is high and they have a collectivist structure (Hofstede et al., 2010). In this sense, the more uncertainty is, the more innovation avoidance is observed (Shane, Venkataraman, \& MacMillan, 1995).

As a result, it can be said that there is no single case of causality specific to countries for a complex adaptive system such as innovation. It is seen that there are different components that create innovation such as the geography, social structure, norms, perceptions and political culture of each country. For example; in individualist countries such as USA, UK, Germany, France, Netherlands and Finland, high general trust has a significant impact on innovation. But low general trust does not effect innovation is in collectivist countries such as Turkey, Azerbaijan, China, Japan and Malaysia. Instead, if trust in institutions is high in these countries, it has a significant impact on innovation.

In this sense, while correlational or descriptive studies between social capital and innovation (Brockman et. al., 2018; Cáceres-Carrasco et al., 2020; Cho, 2018; Dakhli \& De Clercq, 2004; Doh \& Ács, 2009; Ghazinoory et al., 2014; Knack \& Keefer, 1997; Putnam, 1993), correlational or descriptive studies between economic value perception and 
innovation (Beugelsdijk, 2010; Diwan et al., 2018; Gorodnichenko \& Roland, 2011), correlational or descriptive studies between political culture and innovation (Arnstein, 1969; Hausmann \& Rodrik, 2003; Kroll, 2017; Pfotenhauer et al., 2016; van der Molen et al., 2019) cannot provide us with an indication of causality, the studies conducted with the fuzzy-set qualitative comparative analysis (fsQCA) have such a claim (Ragin, 1987, 2008, 2014; Rihoux \& Ragin, 2009). This shows us the power of asymmetric analysis.

We think that the evaluation of asymmetric analyzes by evaluating this pragmatic point of view for future studies as well as studies (Antilla, 2005; Brigham, 2011; Emmenegger et al., 2013; Fiss, 2011; lannacci \& Cornford, 2018; Sager et al., 2019; Schneider et al., 2010; Vis, 2012) in almost every field is very important for the future of scientific studies. 